Article

\title{
Vocalization Analyses of Nocturnal Arboreal Mammals of the Taita Hills, Kenya
}

\author{
Hanna Rosti ${ }^{1,2, *}\left(\mathbb{C}\right.$, , Henry Pihlström ${ }^{3}\left(\mathbb{D}\right.$, Simon Bearder ${ }^{4}$, Petri Pellikka ${ }^{5,6}(\mathbb{D}$ \\ and Jouko Rikkinen ${ }^{1,2}$ (D) \\ 1 Organismal and Evolutionary Biology Research Programme, Faculty of Biological and Environmental Sciences, \\ P. O. Box 65, University of Helsinki, 00014 Helsinki, Finland; jouko.rikkinen@helsinki.fi \\ 2 Finnish Museum of Natural History Luomus, P.O. Box 7, University of Helsinki, 00014 Helsinki, Finland \\ 3 Molecular and Integrative Biosciences Research Programme, Faculty of Biological and Environmental Sciences, \\ P. O. Box 65, University of Helsinki, 00014 Helsinki, Finland; henry.pihlstrom@helsinki.fi \\ 4 Nocturnal Primate Research Group, Oxford Brookes University, Oxford OX3 0BP, UK; \\ skbearder@brookes.ac.uk \\ 5 Department of Geosciences and Geography, Faculty of Science, P.O. Box 64, University of Helsinki, \\ 00014 Helsinki, Finland; petri.pellikka@helsinki.fi \\ 6 Taita Research Station of University of Helsinki, P.O. Box 1156, Wundanyi, Taita Taveta 80304, Kenya \\ * Correspondence: hanna.z.rosti@helsinki.fi
}

Received: 28 October 2020; Accepted: 9 December 2020; Published: 13 December 2020

check for updates

\begin{abstract}
Three poorly known nocturnal mammal species from the montane forests of the Taita Hills in Kenya, were studied via vocalization analysis. Here, their acoustic behaviour is described. The studied animals were the tree hyrax (Dendrohyrax sp.), the small-eared greater galago (Otolemur garnettii), and the dwarf galago (Paragalago sp.). High-quality loud calls were analysed using RAVEN PRO, and compared to calls of presumed closest relatives. Our findings include the first detailed descriptions of tree hyrax songs. Moreover, our results suggest that the tree hyrax of Taita Hills may be a taxon new to science, as it produces a characteristic call, the 'strangled thwack', not previously known from other Dendrohyrax populations. Our data confirms that the small-eared greater galago subspecies living in the Taita Hills is Otolemur garnettii lasiotis. The loud calls of the elusive Taita Hills dwarf galago closely resemble those of the Kenya coast dwarf galago (Paragalago cocos). Thus, the population in the Taita Hills probably belongs to this species. The Taita Hills dwarf galagos are geographically isolated from other dwarf galago populations, and live in montane cloud forest, which is an unusual habitat for P. cocos. Intriguingly, two dwarf galago subpopulations living in separate forest patches in the Taita Hills, Ngangao and Mbololo, have clearly different contact calls. The Paragalagos in Mbololo Forest may represent a population of $P$. cocos with a derived call repertoire, or, alternatively, they may actually be mountain dwarf galagos (P. orinus). Hence, differences in habitat, behaviour, and contact call structure suggest that there may be two different Paragalago species in the montane forests of the Taita Hills.
\end{abstract}

Keywords: acoustic communication; singing mammal; prosimian; nocturnal animals; Dendrohyrax; Otolemur; Paragalago

\section{Introduction}

In the arboreal environment, visual signals are often difficult to perceive through the dense vegetation. Sound, however, travels easily and widely through foliage. This has led to the evolution of intraspecific vocal communication systems in many arboreal animals [1]. Among nocturnal mammals, prosimian primates [2-4] and tree hyraxes [5] rely extensively on acoustic communication, and have complex vocal repertoires. Paterson's 'recognition species concept' predicts the importance of shared 
communication systems in conspecific mate recognition [4,6,7]. Loud calls that are used in long-range advertising are qualitatively different between species [8]. For example, many recently described galago species have been originally identified by their advertisement calls [9-13]. In Paragalago cocos and $P$. zanzibaricus taxonomic separation based on acoustic properties of an advertisement call was subsequently confirmed by genetic analysis [14]. In contrast to advertisement calls, alarm calls are conserved, phylogenetically homologous, and predicted to be less variable than those influenced by sexual selection, making them more useful as grouping criteria $[15,16]$.

In the field, different species of nocturnal primates are often very difficult to tell apart from each other by visually observing them from a distance, and to capture these animals for the purpose of closer examination is often not feasible. Thus, vocal analysis has become an important, non-invasive tool in their study.

As vocalizations convey information about the caller's identity, physical condition, motivation and/or external events, there must be variation in frequency modulations and temporal patterns within the calls $[17,18]$. Animal vocalizations typically vary over time and space, and calls may have multiple sequences that interact with each other [19]. Signal repertoires of mammals have graded variation within and between call types [20]. Signal repertoires may also be mixed when they combine forms of signal types within and between call types $[10,21]$. Mixed calls can be identified from differences in the context in which the calls occur, and the responses of other animals.

This study focuses on the vocalizations of three poorly known, nocturnal, arboreal mammals in the moist montane forests of the Taita Hills, Kenya. Our aim is to, for the first time, describe the most frequently used loud, long-range calls of each species on the basis of acoustic recording data, and then, when possible, make inferences about the taxonomic affinities of these species. The species studied are the local tree hyrax Dendrohyrax sp. (Figure 1A,B), the small-eared greater galago Otolemur garnettii (Figure 1C,D), and the local dwarf galago Paragalago sp. (Figure 1E,F). Both the tree hyrax and the dwarf galago are of uncertain taxonomic identity (see below). The nomenclature of hyraxes and galagos is confusing, and not all species have well-established, vernacular English names [22]. Thus, unless stated otherwise, we will refer to our study animals by their 'Latinized vernacular' names, i.e., as 'Dendrohyrax', Otolemur', and 'Paragalago', respectively.

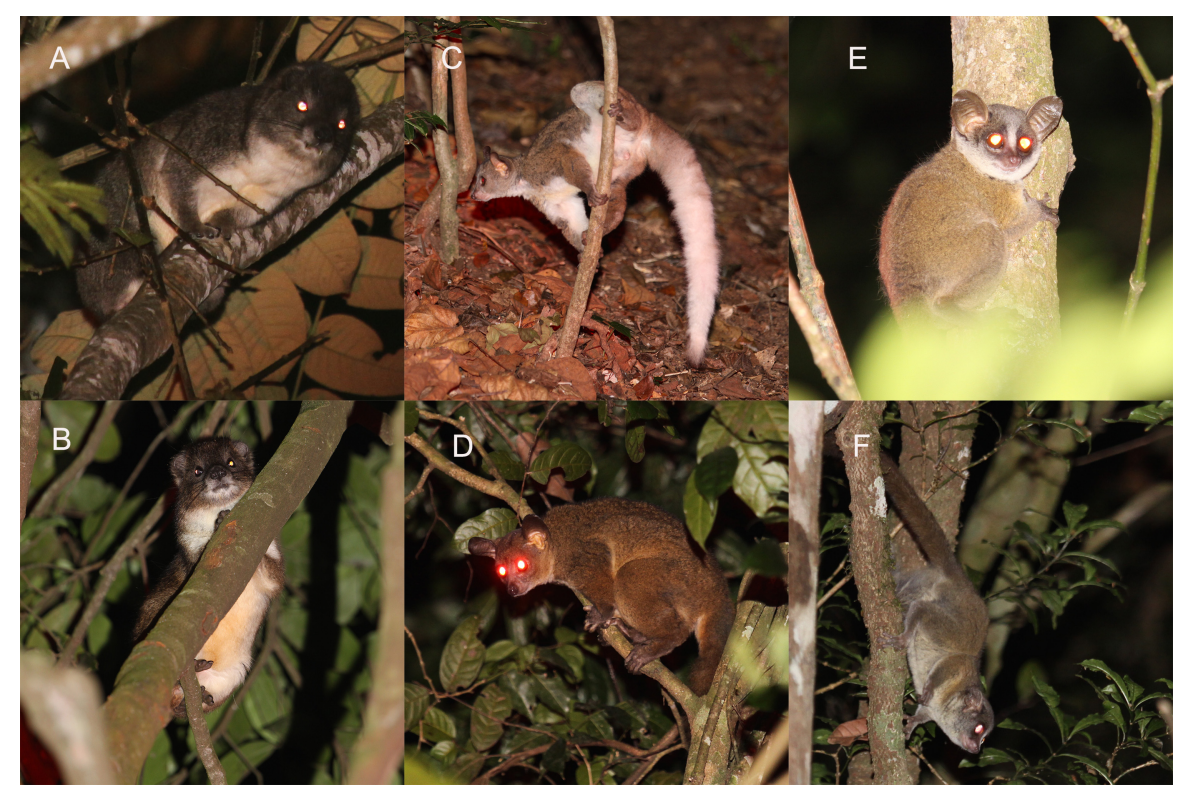

Figure 1. (A) Male Dendrohyrax with large and triangular tusk-like incisors. (B) Female Dendrohyrax with smaller and rounder incisors. (C) White tail-type Otolemur, young male. (D) Black tail-type Otolemur, sex unknown. (E) Paragalago, sex unknown. (F) Paragalago, sex unknown. All photographs taken by Hanna Rosti in Ngangao Forest, Taita Hills, in 2019. 


\subsection{Tree Hyrax Taxonomy}

Tree hyraxes (genus Dendrohyrax) are medium-sized (3-5 kg), afrotherian mammals [23-25]. Tree hyraxes are sometimes active by day [26-29], but, for the main part, they are nocturnal, especially in areas where they are hunted [28]. They are believed to be solitary, and to rely on acoustic communication for advertising their position relative to one another during the night $[5,24,25,29-33]$.

Since the publication of Hahn in 1934, there has been general agreement among zoologists that there are three species of tree hyrax: the southern tree hyrax Dendrohyrax arboreus, the western tree hyrax D. dorsalis, and the eastern tree hyrax D. validus [34]. Due to their arboreal and often nocturnal habits, tree hyraxes are difficult to study in the wild, and much of what is known, or inferred, about their distributions is based on museum records. The known range of Dendrohyrax dorsalis versus the other two species is almost allopatric; there is only a small area of geographical overlap between $D$. dorsalis and D. arboreus in east-central Africa $[35,36]$. D. arboreus and D. validus both occur in parts of Kenya and Tanzania, but the exact limits of their respective ranges are not well known [37]. Kingdon [38,39] considered $D$. validus to be the least specialised of the tree hyraxes, and suggested that it has been displaced by $D$. arboreus in many localities in eastern Africa. Where both species occur, D. validus usually lives at greater altitudes in montane forests [23]. However, D. validus may occur at sea level in areas where it is the only tree hyrax species present [40]. In recent years, there have been suggestions that the species-level diversity of tree hyraxes is underestimated [37,41] Bearder et al. (2015) [42] recorded unusual Dendrohyrax calls in the field in southern Nigeria; the authors noted that these calls do not resemble those of $D$. dorsalis, the only tree hyrax species supposedly found in this area. This suggests that there might be at least one other, scientifically undescribed tree hyrax species living in western Africa.

Dendrohyrax validus has been divided into a number of subspecies, of which four are widely accepted. The type locality of the nominate subspecies D. v. validus is "Mt. Kilima-njaro" [43,44]. The subspecies D. v. neumanni occurs on the island of Zanzibar [45], whereas the type locality of the subspecies D. v. schusteri is the Uluguru Mountains [46]. Finally, the type locality of the subspecies D. v. terricola is eastern Usambara Mountains, a few hours' distance away from the Amani Research Station, and a few minutes' distance away from the village of "Monga", according to the original description [47]. Notably, the type localities of all these four subspecies are in present-day Tanzania; none is located in present-day Kenya. Until relatively recently, Dendrohyrax validus was not believed to occur in Kenya, and the country's only native tree hyrax species was thought to be Dendrohyrax arboreus. The presence of D. validus in Kenya was finally confirmed in the 1970's, when a small population was discovered circa $30 \mathrm{~km}$ north of Mombasa [40]. Subsequent sightings and sound recordings have shown that $D$. validus also occurs in the Taita Hills [5]. The Taita Hills tree hyraxes are thought to represent the subspecies D. v. terricola [33]. However, this assumption is based on the relative geographical proximity to the Usambara Mountains across the Tanzanian border rather than on any detailed morphological or genetic studies. In fact, to our knowledge, as of yet no tree hyrax specimens have been collected from the Taita Hills [48,49]. The only published specimen records of $D$. validus from Kenya that we are aware of are those of Seibt et al.; these authors discovered one complete and one partial skull, and a 'mummified' carcass of an adult male in the vicinity of the village of Vipingo, circa $30 \mathrm{~km}$ north of Mombasa along the coast of Kenya [40].

Roberts analysed recordings from 16 forest populations of Dendrohyrax validus and found at least three distinct subpopulations with extreme acoustic qualitative differences: (1) a subpopulation in the Taita Hills in Kenya and the East Usambara Mountains in Tanzania, (2) a subpopulation in the Uluguru and Udzungwa Mountains in southern Tanzania, and (3) a subpopulation in the islands of Zanzibar and Pemba at the Tanzanian coast [5]. Roberts suggested that these populations should be subject to further behavioural and genetic research [5]. 


\subsection{Galago Taxonomy}

Galagos are strictly nocturnal $[50,51]$. Consequently, they are often difficult to observe in their natural habitat. Like tree hyraxes, galagos are, however, very vocal animals, and their nocturnal calls are characteristic sounds of the African night.

The greater galagos, or thick-tailed galagos, of the genus Otolemur are the largest of the galagos, weighing about 1-1.5 kg [52]. The number of species in this genus has been a matter of debate [4,10,53-59], but most authors agree that there are three species. According to Groves, these are the brown greater galago Otolemur crassicaudatus, the silvery greater galago O. monteiri, and the northern, or small-eared, greater galago O. garnettii [60]. All three species are found in various parts of eastern Africa, and G. crassicaudatus and O. garnettii locally occur in sympatry [61]. Kingdon suggested that a fourth, undescribed Otolemur species may live in south-eastern Tanzania [59]. The only Otolemur species recorded from the Taita Hills is O. garnettii [60]. O. garnettii is divided into several subspecies; the one that occurs in the Taita Hills is presumed to be O. g. lasiotis, but the known distribution limits of another subspecies, O. g. panganiensis, are not located far off [13]. The subspecific identity of the Taita Hills greater galago thus requires confirmation.

Historically, most of the small-bodied galagos, as well as the Otolemur species, were placed in only one genus, Galago $[15,60,62]$. Subsequently it has become evident that the extant galago taxa represent deeply divergent evolutionary lineages, despite their superficial similarity $[8,63,64]$. Currently, several different genera of galagos are recognised. Apart from the lesser galago genus Galago (sensu stricto) and the greater galago genus Otolemur, most authors recognise the dwarf galago genus Galagoides, the needle-clawed galago genus Euoticus, and the squirrel galago genus Sciurocheirus. Recently, Masters et al. reviewed the systematics of the Galagoides species group of dwarf galagos and found that the western and eastern African species of this genus do not form a monophyletic clade [15]. Thus, Masters et al. separated the latter into a separate genus, which they named Paragalago. The type species of this new genus is the Zanzibar galago, originally described by Matschie in 1893 as Galago zanzibaricus [45].

In 2002, Perkin et al. presented preliminary evidence for the existence of a scientifically undescribed dwarf galago taxon in the Taita Hills [65]. Based on general similarities in the vocal repertoire between the Taita Hills dwarf galago and other eastern dwarf galagos, they suggested that this possibly new species, too, belongs to the East African clade [65]. However, in the absence of a physical type specimen, this taxon is at present still unnamed [66].

\section{Materials and Methods}

\subsection{Study Area}

The study was conducted in the Taita Hills, Kenya $\left(03^{\circ} 22^{\prime} \mathrm{S}, 38^{\circ} 20^{\prime} \mathrm{E}\right)$ (Figure 2). The Taita Hills represent the northernmost extension of the Eastern Arc Mountains in south-eastern Kenya. The Taita Hills rise abruptly from the surrounding dry plains at ca. 600-1000 m altitude above sea level (a.s.l.) to a series of mountain ridges, reaching $2208 \mathrm{~m}$ a.s.l. at the highest peak, Vuria [67]. Average yearly temperature in Wundanyi, is $19.7^{\circ} \mathrm{C}$, the coldest month is July with the average temperature of $17.3^{\circ} \mathrm{C}$, and the warmest month is March with the average temperature of $21.8^{\circ} \mathrm{C}$ [68]. Average yearly rainfall is $1140 \mathrm{~mm}$. Extended rains occur in March, April, and May, and shorter rains in November and December. The upper slopes of the mountains receive moisture brought by the trade winds, and the moisture is captured in sufficient extent to sustain evergreen montane forests. The moist and relatively cool climate sustains lush montane forests with a considerable epiphyte biomass [69-71]. The University of Helsinki has a research station in Taita Hills, which served as a base for the fieldwork described in this paper. 


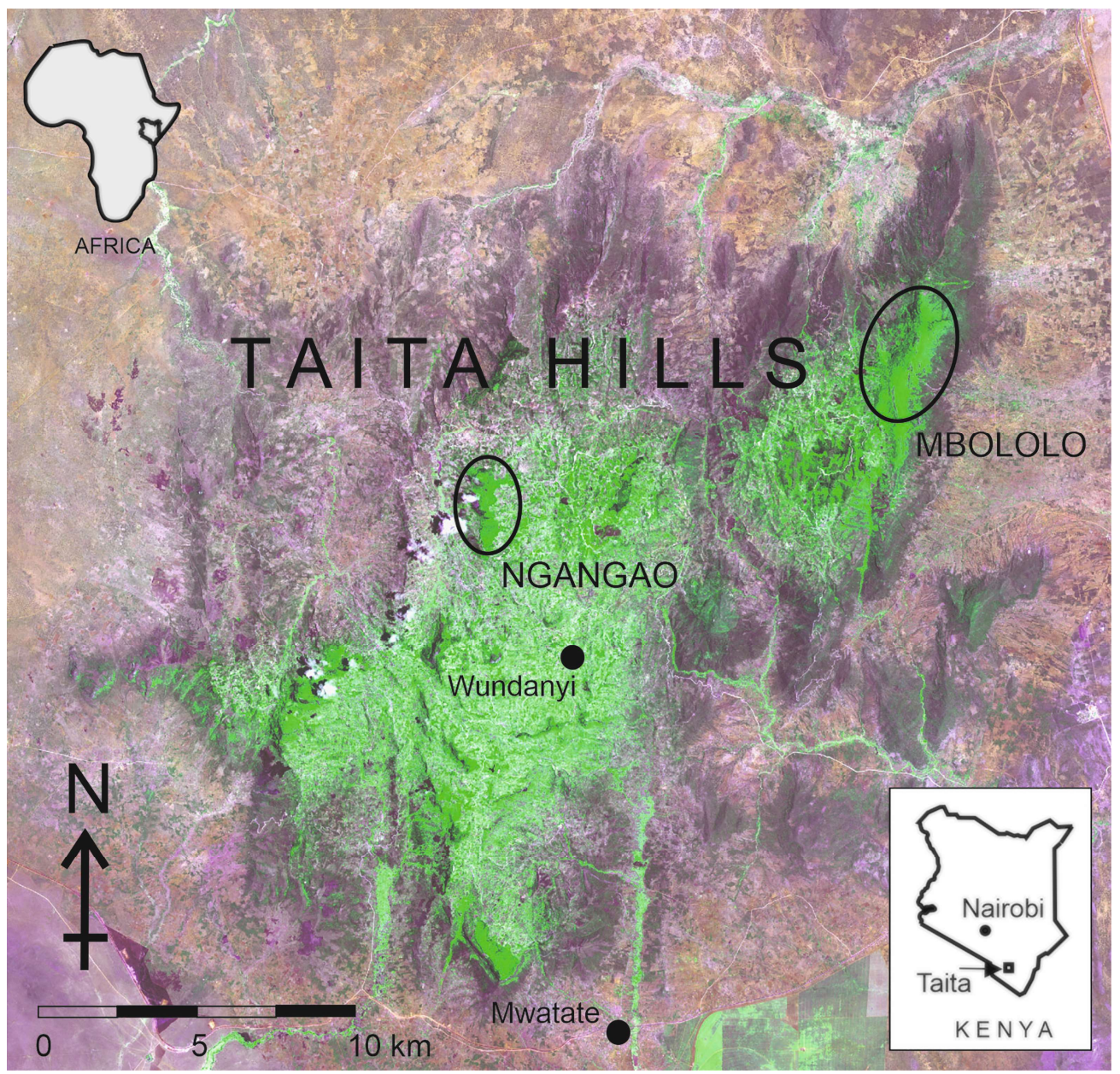

Figure 2. Map of the Taita Hills, Kenya, showing the locations of Ngangao and Mbololo Forests.

The crystalline block-faulted Eastern Arc Mountains were formed 290-180 Myr BP [72], and represent a well-known biodiversity hot spot [73-75]. While the natural vegetation on the upper slopes of the Taita Hills consists of closed montane forest, long-lasting and intensive human influence has reduced the indigenous forest into remnant patches $[68,76,77]$. The largest remaining patches of montane forests are Mbololo (220 ha) and Ngangao (120 ha). In addition, there are numerous small fragments of indigenous forest vegetation, many of them at sites regarded by the local people as sacred, and which therefore are afforded protection [78]. Despite the efforts to conserve remaining forest patches and to reforest degraded areas with indigenous trees, the cover of montane forest further decreased between 2003 and 2018 [79].

Our studies on nocturnal mammals were conducted in the two largest remaining fragments of indigenous montane forest in Taita Hills, Mbololo ( $3^{\circ} 19^{\prime} 37^{\prime \prime} \mathrm{S}, 38^{\circ} 27^{\prime} 4^{\prime \prime} \mathrm{E}, 1550-1700 \mathrm{~m}$ a.s.l.) and Ngangao ( $3^{\circ} 22^{\prime} 9^{\prime \prime} \mathrm{S}, 38^{\circ} 20^{\prime} 33^{\prime \prime} \mathrm{E}, 1700-1870 \mathrm{~m}$ a.s.l.) (Figure 2). Both fragments are classified as moist montane forests [70], and are situated on the steep upper slopes of north-south-oriented mountain ridges. While parts of Ngangao have been subjected to relatively intensive selective logging in the past, the largest upper canopy trees are over $50 \mathrm{~m}$ tall [80,81]. The multi-layered canopy of Ngangao is formed by many different tree species including Tabernaemontana stapfiana, Macaranga capensis, Strombozia scheffleri, Pouteria adolfi-friedericii, and Newtonia buchananii. While no long-term climatic data are available, some data on climatic conditions of Ngangao have been published [82,83]. Parts of Mbololo receive abundant moisture from low-lying clouds and fog and appear wetter than most sites in Ngangao. Human-wildlife conflict is ongoing in and near the forest patches in the area; notably, blue monkeys Cercopithecus mitis frequently raid farms close to the indigenous forests [84]. 


\subsection{Data Collection}

Nocturnal observations and recordings were made from sunset at 6 p.m. until 1 a.m., a total of seven hours, or 2-7.30 a.m., a total of five and a half hours. We had one observation period for each night, usually shifting from evening to morning. During rainy nights, no observations were made, as animals were then generally quiet. Forests were studied in detail also during the day, to gain information of the forest characteristics, tree species, and tree hollows used by Paragalagos. Recordings were made by placing a recorder close to the location known to have high animal density with GPS location. Notes were taken from about a 5-m distance away, as this reduced sound disturbance caused by small movements of the observer. Forests were searched with transects during 20 nights between 2 January to 25 January to gain knowledge of which sites were preferred by the animals. Later we confined our movement to forest paths as this helped to reduce excessive noise. Our speed along the paths was circa $500 \mathrm{~m} / \mathrm{h}$. Whenever Paragalagos were encountered recordings were made opportunistically at standstill. Recordings were also made in proximity of the dwarf galago daytime sleeping sites at dawn and dusk, when family groups typically vocalize communally.

Fenix TK 25 red beam handheld flashlights (Fenix Lighting, Littleton, CO, USA) were used for visual observations. Only red light was used, as it does not disturb the animals. Flashlights were held at the level of the eye to be able to spot the animals' eyeshine. Animals were photographed with an Eos D50 camera (Canon, Tokyo, Japan) equipped with a Canon EF 70-200 zoom and a Canon Speedlight 550EX flashlight. Data on vocalizations (total $256 \mathrm{~h}$ ) were collected with an LS-12 recorder (Olympus, Tokyo, Japan) and an AT8015 ${ }^{\odot}$ microphone (Audio-Technica, Tokyo, Japan).

Animals were often first identified by the colour of their eyeshine. Dendrohyrax has yellowish eyeshine, but sometimes eyeshine was not visible. Dendrohyraxes were seen typically unmoving, resting on the large branches. Otolemur usually has reddish, and occasionally yellowish, eyeshine. Paragalago has the most reddish and distinct eyeshine, and can be separated from Otolemur by the fact that its eyes are set more closely to each other. Otolemur and Paragalago can be also be told apart from each other by their movement patterns and speed, and their pronounced difference in body size.

The material collected in January-March 2019 included $90 \mathrm{~h}$ of recordings during 55 observation nights in the Ngangao and Mbololo Forests. These data were used for preliminary analysis, and they were compared with recordings stored by the Nocturnal Primates Research group and by Wildsolutions, http://www.wildsolutions.nl. Wildsolutions is the website of the Eastern Africa Primate Diversity and Conservation Program. The site also has vocal profiles for galagos and tree hyraxes. Names of the calls used here are the same as used by Wildsolutions. The loud calls of each species were chosen for analysis from preliminary material. The analysed vocalizations included Dendrohyrax strangled thwack $(n=174)$ and hac $(n=79)$ calls, Otolemur trailing $(n=78)$ and cluster squawk $(n=47)$ calls, and Paragalago incremental $(n=31)$, chatter $(n=43)$, chirrup $(n=54)$ and yap $(n=45)$ calls. Dendrohyrax song syllables are described briefly and here named for the first time.

An analysis of $176 \mathrm{~h}$ of recordings taken in June-August 2019 is presented here (see Supplemental Data S1). This material was collected in the Ngangao Forest. Only distinct, close-range recorded calls with no interfering katydid songs $[85,86]$ or other animal calls were included in the analysis. In all species, graded and mixed calls were included in the analysis, and categorized as the call type that it resembled the most. As calling animals were impossible to recognize individually, more than one call by the same animal may have been included in the analyses. For Dendrohyrax, the probability of repeatedly recording the vocalizations of the same individual was reduced by analysing only one call for each sequence and locality. The recordings included thousands of Dendrohyrax calls, which reduced the probability of analysing the same animal repeatedly. For Otolemur, all high-quality trailing calls were analysed, and a number of cluster squawks were randomly selected for analysis. The trailing calls were recorded in many different locations; however, it is possible that calls of some individual animals were analysed more than once. For Paragalago, all high-quality incremental calls $(n 31)$ were analysed. As we could only obtain calls from the single known population in Ngangao, consisting of only ca. 10 individuals, we could not avoid recording individual animals repeatedly. In Paragalago 
chatter, chirrup, and yap samples, calls were sampled randomly as our recordings included hundreds of individual chatters, chirrups, and yaps. Thus, we were able to provide a detailed picture of variation in the calls of this single population. Unit distances of calls were calculated from recordings when only one individual was vocalizing.

\subsection{Data Analysis}

The audio data were analysed with sound software RAVEN PRO 1.5 (Cornell University, Ithaca, NY, USA) using the following spectrogram parameters: DFT size $512,50 \%$ overlap, hann $86.1 \mathrm{~Hz}$, sample rate 44,100 Hz, 16-bit signed. Ten parameters were measured for each call. These were: (a) fundamental frequency; the lower frequency bound of the selection $(\mathrm{Hz}),(\mathrm{b})$ high frequency; the upper frequency bound for the selection $(\mathrm{Hz}),(\mathrm{c})$ call duration - delta time; difference between start time and end time for the selection (s), (d) maximum frequency; frequency with maximum power $(\mathrm{Hz})$, (e) Q1 frequency; divides the selection into two frequency intervals containing $25 \%$ and $75 \%$ of the energy in the selection $(\mathrm{Hz})$, (f) centre frequency; divides the selection into two frequency intervals of equal energy $(\mathrm{Hz}), \mathrm{g}$ ) max entropy; describes entropy distribution within the call. Higher values correspond to greater disorder (bits), (h) delta frequency; difference between upper and lower frequency limits on the selection $(\mathrm{Hz})$, (i) energy; total energy within selection bounds $(\mathrm{dB})$, (j) peak power $(\mathrm{dB})$; maximum decibels within the call measured at the maximum point.

When analysing calling strategies from whole sequences, we investigated inter-unit interval (time between two calls, measured in s), redundancy, combination of calls, and answers coming from conspecifics. Inter-unit intervals of tree hyrax calls were calculated from sequences when the animal was calling alone. Otolemur trailing calls and Paragalago incremental calls were compared with calls described in previous studies [12,13,52].

Calls recorded for this research are stored and audible in the call library of Wildsolutions: http://www.wildsolutions.nl and Supplemental in animalstaita.com. Data is available in Supplemental Data S1.

Data analysis was carried out using R Studio version 1.2.5033 (The R Foundation for Statistical Computing, Vienna, Austria) and SPSS, version 25 (SPSS Inc., Cary, NC, USA, following protocols described by Zuur et al. [87] (Supplementary Figure S2). We used multinomial regression analysis to test whether we had classified the calls correctly.

Covariates entered into analysis were delta frequency, energy, maximum entropy, peak power, delta time, maximum frequency, first quartile frequency, and central frequency. We examined homogeneity of variances from scatterplots by using residuals of multiple regression by plotting residuals vs. fitted values and making boxplots of the residuals. We examined normality for each group and covariate by using histograms. As the data did not meet the assumptions of homogeneity required for discriminant function analysis, we used multinomial linear regression (MLR) instead. Outliers were identified using Cleveland dotplots and Cook's distance. Outliers left in the data are natural outliers, showing true variation in the calls. All assumptions required for multinomial regression analysis were met. Data exploration graphs are available in the Supplemental information (Figure S2).

Variables entered in the multinomial regression analysis were delta time (s), maximum frequency $(\mathrm{Hz})$, and max entropy (bits). All variables were significant in MLR analysis. MLR analysis classified $82.8 \%$ of the calls correctly (Table 1 ).

Table 1. Multinomial linear regression (MLR) results in different calls. MLR categorized $82.8 \%$ of the calls correctly using the covariates call duration, maximum frequency, and maximum entropy.

\begin{tabular}{|c|c|c|c|c|c|c|c|c|}
\hline & $\begin{array}{c}\text { Dendrohyrax } \\
\text { Strangled Thwack } \\
n 174\end{array}$ & $\begin{array}{c}\text { Dendrohyrax } \\
\text { Hac } \\
n 80\end{array}$ & $\begin{array}{c}\text { Otolemur } \\
\text { Trailing } \\
n 78\end{array}$ & $\begin{array}{c}\text { Otolemur } \\
\text { Squawk } \\
n 48\end{array}$ & $\begin{array}{c}\text { Paragalago } \\
\text { Incremental } \\
n 31\end{array}$ & $\begin{array}{c}\text { Paragalago } \\
\text { Chatter } \\
n 48\end{array}$ & $\begin{array}{c}\text { Paragalago } \\
\text { Chirrup } \\
n 55\end{array}$ & $\begin{array}{c}\text { Paragalago } \\
\text { Yap } \\
n 45\end{array}$ \\
\hline Percentage & 89.1 & 58.2 & 93.6 & 76.6 & 41.9 & 90.7 & 92.6 & 97.8 \\
\hline
\end{tabular}


If we had used energy or peak power in the analysis there would have been $2.8 \%$ better results from MRL analysis (85.6\%). However, peak power and energy are related to the distance of the calling animal from the microphone. As distance was unknown, we chose to leave peak power and/or energy out of the MLR.

\section{Results}

\subsection{Characterization of Dendrohyrax Vocalizations}

Dendrohyrax calls are a common and acoustically striking feature of the acoustic landscape of the Ngangao and Mbololo Forests, with frequent loud calling bouts of single or several counter-calling animals. The most common loud calls used are strangled thwack and hac (Figures 3-5, Table 2, Supplemental Data S1). Table 2 has more numerical information about the calls. Dendrohyrax also produces bird-song-like vocalizations (Figure 6).

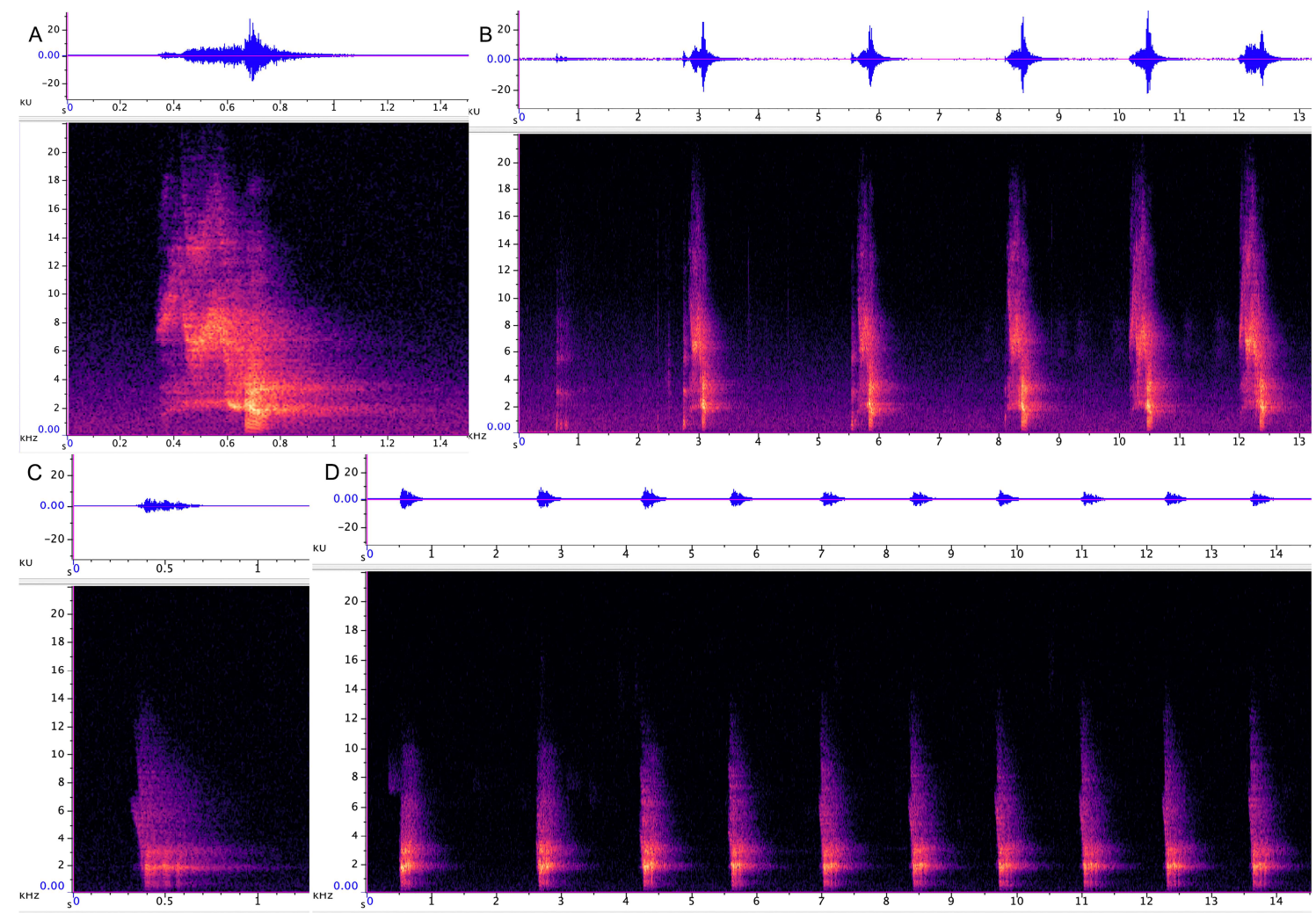

Figure 3. Waveforms (upper images) and spectrograms (lower images) of Dendrohyrax calls. (A) Strangled thwack single call. Note frequency-modulated twist that gives the call its name (Sound S3). (B) Sequence of strangled thwacks. The image shows the first five (13 s) strangled thwacks of the total of 15 signals in the sequence (duration $45 \mathrm{~s}$ ) (Sound S4). The first call is not included as it is a small knock that is often used to start or end a sequence. (C) Hac call (Sound S5) is less powerful and has a smaller frequency range than the strangled thwack. It sounds like a fast 'kra-kra-kra'. (D) Sequence of hac calls shoving first nine calls (14 s) of the sequence containing 15 signals in the sequence (duration $21 \mathrm{~s}$ ) (Sound S6). 

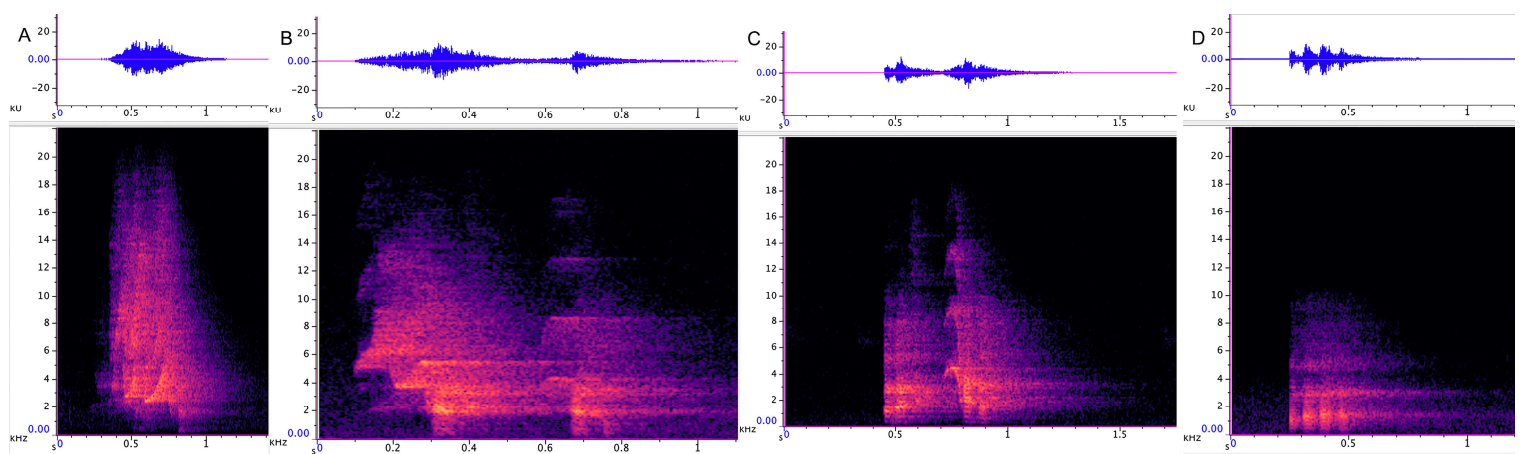

Figure 4. Variants of Dendrohyrax strangled thwack $(\mathbf{A}, \mathbf{B})$ and hac $(\mathbf{C}, \mathbf{D})$ calls (upper images: waveform, lower images: spectrogram). (A) Strangled thwack with embedded wheeze element (Sound S7). (B) Double strangled thwack (Sound S8). This call type was frequently recorded in one area of Ngangao Forest and was probably used by the same Dendrohyrax individual. (C) Double hac with thwack-like second unit (Sound S9). (D) Hac call with four subunits (Sound S10). The number of subunits in hac calls varies from one to four.

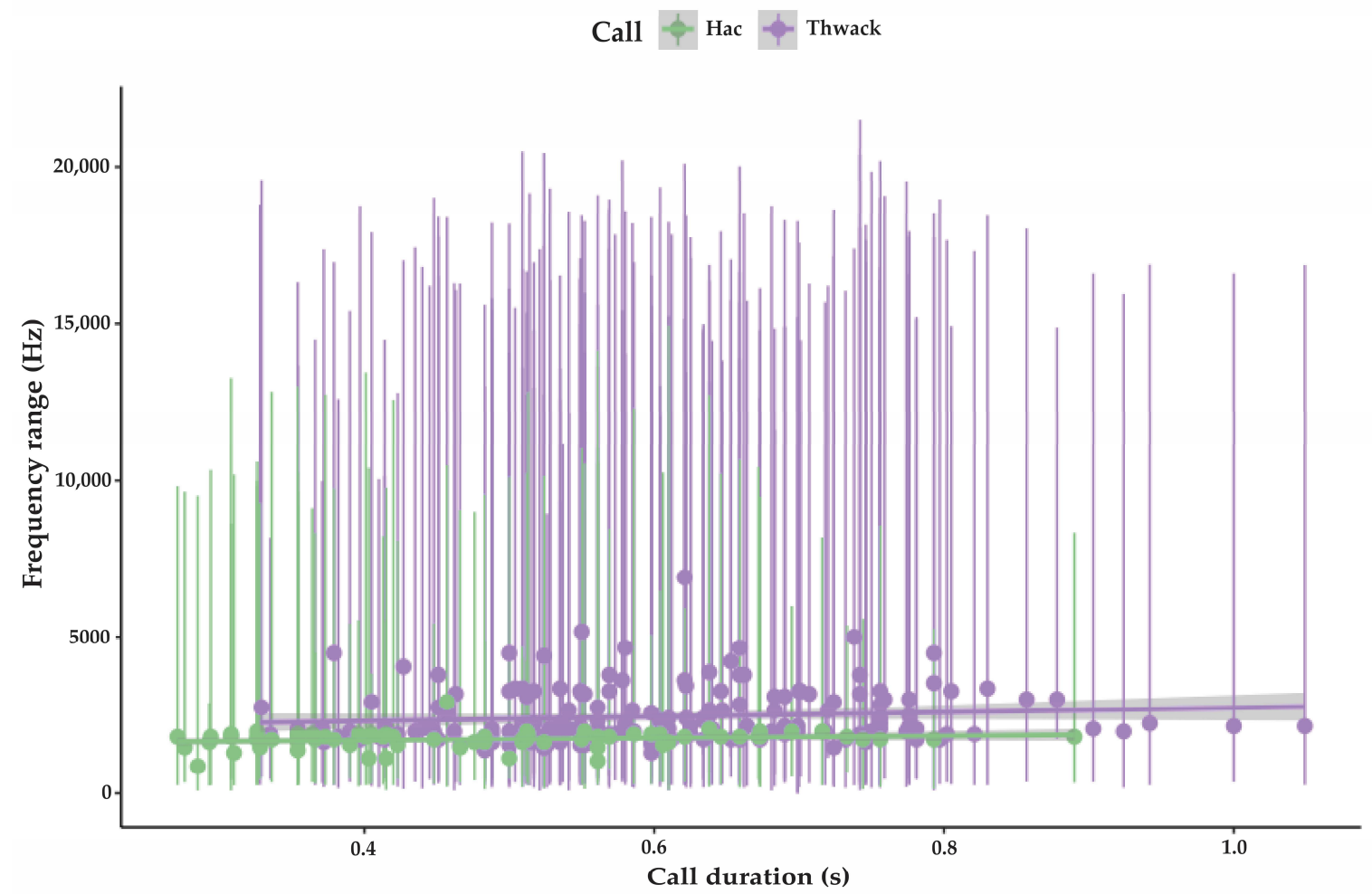

Figure 5. Comparison of Dendrohyrax strangled thwack and hac. The dots indicate maximum frequencies. Strangled thwacks have a higher frequency range (average 15,900 Hz) than Hac calls (average $9200 \mathrm{~Hz}$ ). Hac is typically used in the beginning of the calling bout, or after a sequence of strangled thwacks. Duration of strangled thwack is slightly longer (average $0.6 \mathrm{~s}$ ) than hac (average $0.5 \mathrm{~s}$ ). Duration of the hac call is related to the number of subunits in the call.

Table 2. Vocal characteristics of Taita Hills Dendrohyrax calls.

\begin{tabular}{|c|c|c|c|c|c|c|c|c|}
\hline Call Type & $n$ & $\begin{array}{l}\text { Fundamental } \\
\text { Frequency } \mathrm{Hz}\end{array}$ & $\begin{array}{l}\text { Highest } \\
\text { Frequency }\end{array}$ & $\begin{array}{c}\text { Maximum } \\
\text { Frequency } \mathrm{Hz}\end{array}$ & Call Duration s & Redundancy & Unit Distance $\mathrm{s}(n)$ & Answer \% \\
\hline $\begin{array}{l}\text { Strangled } \\
\text { thwack }\end{array}$ & 174 & $\begin{array}{c}323 \\
\text { SD } 53.5\end{array}$ & $\begin{array}{c}16,206 \\
\text { SD } 3469\end{array}$ & $\begin{array}{c}2431 \\
\text { SD } 818\end{array}$ & $\begin{array}{c}0.6 \\
\text { SD } 0.14\end{array}$ & $\begin{array}{c}1-15 \\
\text { avg. } 5.2\end{array}$ & $\begin{array}{c}11.5(n 248) \\
\text { SD } 8.6\end{array}$ & 75 \\
\hline $\mathrm{Hac}$ & 79 & $\begin{array}{c}304 \\
\text { SD } 124\end{array}$ & $\begin{array}{c}9538 \\
\text { SD } 3469\end{array}$ & $\begin{array}{c}1725 \\
\text { SD } 269\end{array}$ & $\begin{array}{c}0.49 \\
\text { SD } 0.16\end{array}$ & $\begin{array}{l}1-<100 \\
\text { avg. } 7.2\end{array}$ & $\begin{array}{l}8.7(n 115) \\
\text { SD } 3.8\end{array}$ & 74 \\
\hline
\end{tabular}



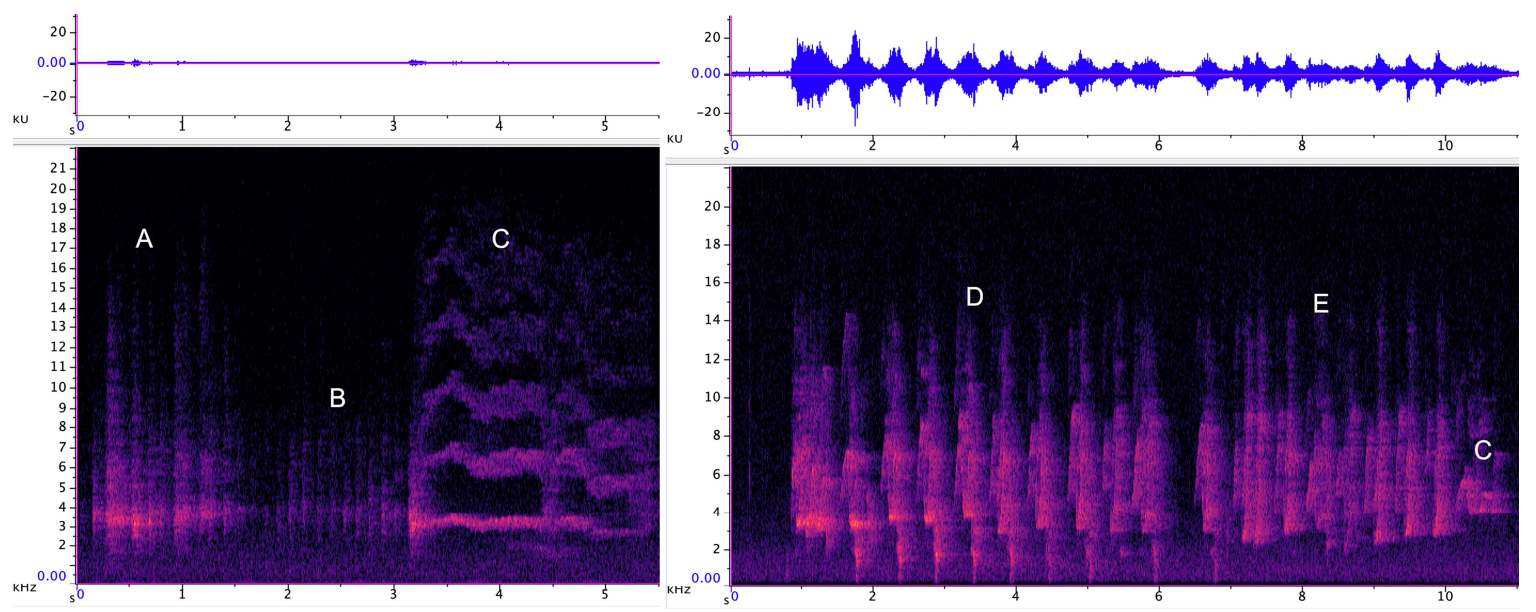

Figure 6. Dendrohyrax song syllables (upper images: waveform, lower images: spectrogram). The spectrogram on the left shows the first $5.5 \mathrm{~s}$ of a $30 \mathrm{~s}$ long sequence (Sound S11), and the spectrogram on the right shows the 10 first seconds of a $32 \mathrm{~s}$ long sequence (Sound S12). (A) Cracle is a short, (1.5 s), vertical broadband pulse with 10 subunits, and is often used in association with rachet. (B) Rachet is a short $1.2 \mathrm{~s}$ long call with 11 tightly packed subunits, and is often used in association with cracle. (C) Wheeze sounds like whistle, here with five harmonics. Wheeze is often used without other call-types in a longer sequence, or is added into songs during any phase. Wheeze element may also be added to strangled thwack. (D) Chuck is a tightly packed phase of 10 subunits. (E) Chirp is a packed phase here consisting of nine tightly packed subunits. Here chirp is followed by one wheeze.

\subsubsection{Strangled Thwack}

This is the most common and most distinct territorial call type of Dendrohyrax in the Taita Hills. It is given in sequences of $1-15$ calls. (Figure 3A Supplemental Sound S3 and Figure 3B Supplemental Sound S4).

Average energy of recorded calls was $104.2 \mathrm{~dB}$ (SD 4.5). In 75\% of the sequences two to seven animals are counter-calling with each other and in $25 \%$ of the sequences did not get a response. Within the calls, there is considerable intraspecific variation between different individuals, as well as considerable intra-individual variation (Figure 4A, Supplemental Sound S7, and Figure 4B Supplemental Sound S8). Some strangled thwacks are very loud. The call may begin with a knock element, or the call may have a wheeze (whistle) type element in the middle. Noisy elements are essential parts of the strangled thwacks. This call is pulse-like, vertical with a striking twist, which gives it its name 'strangled thwack'. The strangled thwack sequence is often changed to a hac sequence as the animal continues calling.

\subsubsection{Hac}

Another very common call type that also seems to represent a territorial call. It is given in calling sequences from 1-100 calls (Figure 3C Supplemental Sound S5 and Figure 3D Supplemental Sound S6). Average energy of recordings was $101 \mathrm{~dB}$ (SD 4.9). Of 19 analysed sequences, 74\% received a reply from one to five individuals, whereas $26 \%$ of the sequences did not get responses. The hac call is variable (Figure 4C Supplemental Sound S9 and Figure 4D Supplemental Sound S10) and may have one to four subunits. Sometimes the hac call is emitted as a 'ping-pong' sequence, where a series of hac phases lead to a 'finale' where the inter-unit interval is shorter than one second and the call is repeated more than 20 times. This call may be used alone or in combination with strangled thwacks. The hac call may be replied to with a similar call or with a strangled thwack. The strangled thwack and the hac differ from each other mainly in frequency range (Figure 5). Strangled thwack frequency range is $15,900 \mathrm{~Hz}$ and hac frequency range is $9200 \mathrm{~Hz}$. 


\subsubsection{Songs}

These are variable and may contain several different syllables that are combined in various ways (Figure 6A-C, Supplemental Sound S11, and Figure 6D,E, Supplemental Sound S12). Syllables categorized in this research are crackle, rachet, wheeze, chuck, and chirp. Some syllables, most commonly the wheeze, may be used alone in sequences lasting up to $20 \mathrm{~s}$. To a human observer, a wheeze sequence frequently indicates that the beginning of a song is imminent. We recorded songs on six nights with several singing bouts on each night in Ngangao Forest in several sites, in January, June, and July. Songs last for $0.5-15 \mathrm{~min}$ at a time. Songs usually begin with crackles, rachets, and wheezes. Later syllables, most commonly wheeze, knock, and chuck, are each repeated for 10-20 s and changed to another syllable. An analysis of all different elements in these complex songs is, however, beyond the scope of this paper.

\subsubsection{Behavioural Observations}

Dendrohyrax calls are frequently heard in the Ngangao and the Mbololo Forests, indicating high population density at both sites. We saw and photographed individual animals more than 20 times in January-March 2019. Mostly the animals were observed resting on the larger branches, at heights of three to seven meters. Individual animals were also seen while on the move: in trees, where they moved by jumping clumsily from one branch to another, or by walking on the branches, and on the ground, where one individual was seen running on a road. Only on one occasion, 16 June, 2019, at 3 am, we observed a male and a female Dendrohyrax together. The animals did not appear to be intimidated or agitated by the presence of humans while they were in trees.

\subsection{Characterization of Otolemur Vocalizations}

Otolemur is common in the Taita Hills, where loud calls that give it the name "bush baby" are frequent. The loud calls used in the area are almost exclusively the trailing call and the cluster squawk (Figures 7 and 8, Table 3, Supplemental Data S1). Table 3 contain more numerical information about the calls.

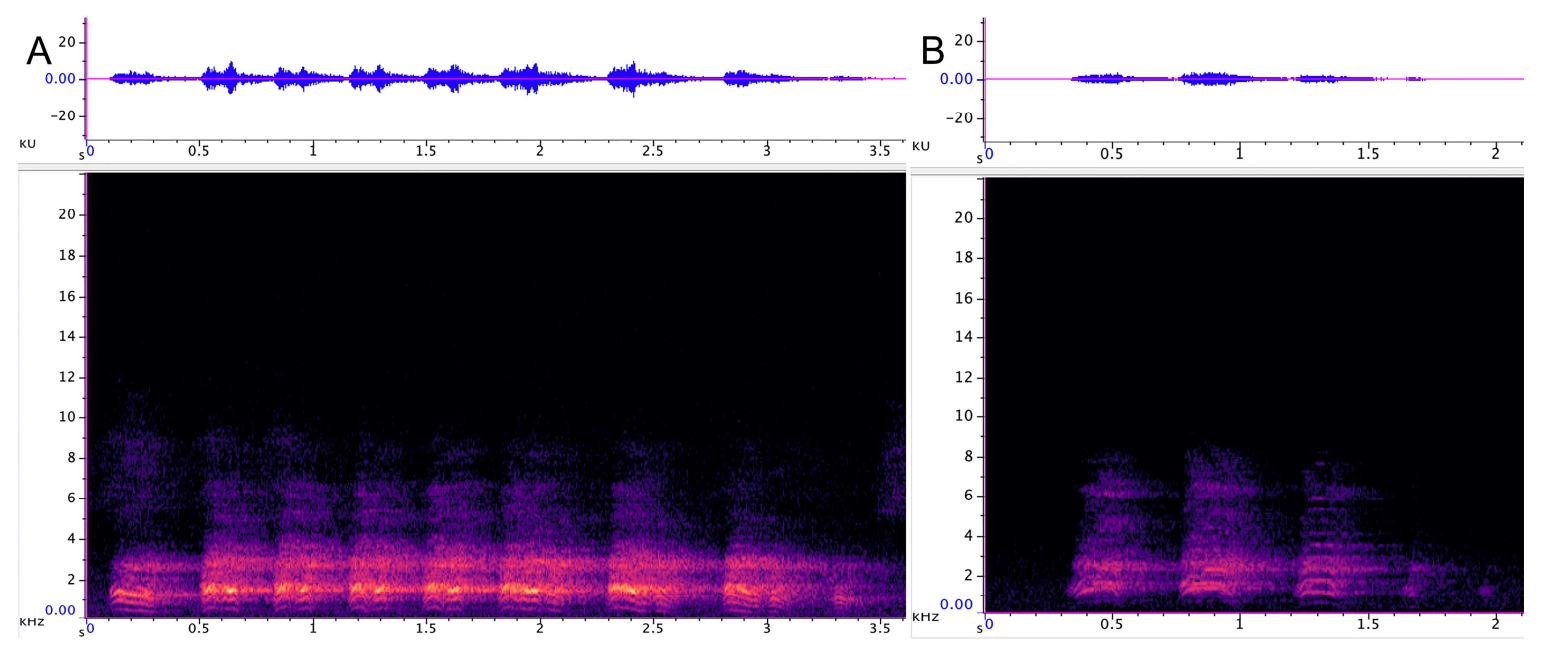

Figure 7. Otolemur calls (upper images: waveform, lower images: spectrogram). (A). Trailing call is a primary advertisement call (Sound S13). This call has nine subunits where intensity first grows and then trails away. (B) Cluster squawk is a contact call, and may be used to answer trailing calls (Sound S14). It is also used as a mild alarm with subunits further apart with high repetition rate. 


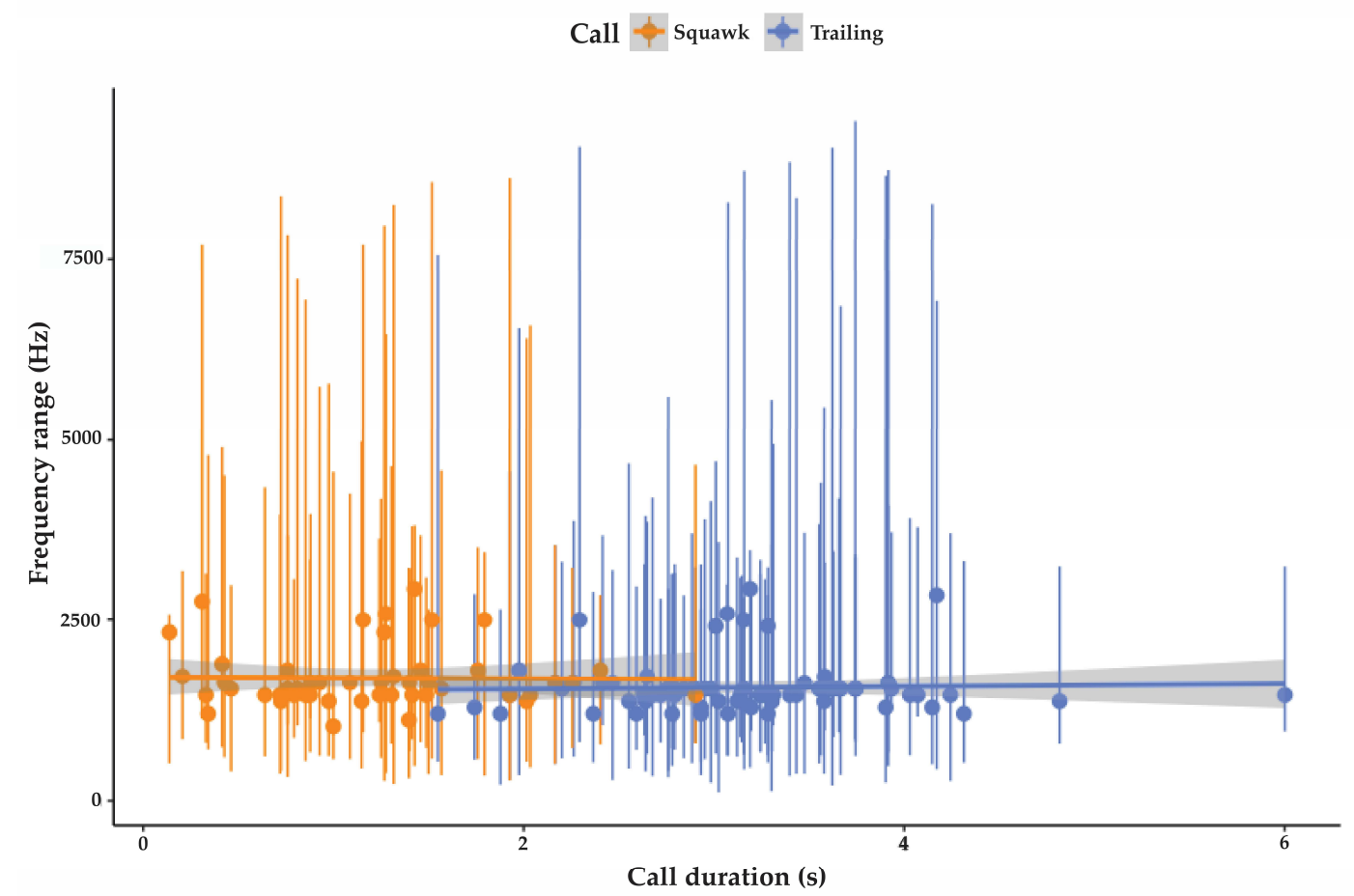

Figure 8. Comparison of Otolemur cluster squawk and trailing calls. The dots indicate maximum frequencies. The trailing call is clearly longer (average $3.2 \mathrm{~s}$ ) than the cluster squawk (average $1.7 \mathrm{~s}$ ).

Table 3. Vocal characteristics of Taita Hills Otolemur calls.

\begin{tabular}{cccccccc}
\hline Call Type & $\boldsymbol{n}$ & $\begin{array}{c}\text { Fundamental } \\
\text { Frequency Hz }\end{array}$ & $\begin{array}{c}\text { Highest } \\
\text { Frequency }\end{array}$ & $\begin{array}{c}\text { Maximum } \\
\text { Frequency Hz }\end{array}$ & Length s & Energy dB & Answer \% \\
\hline \multirow{2}{*}{ Trailing call } & \multirow{2}{*}{78} & 227 & 6195 & 1568 & 3.2 & 98.2 & 42 \\
\multirow{2}{*}{ Cluster squawk } & \multirow{2}{*}{47} & SD 25.7 & SD 4026 & SD 357 & SD 0.7 & SD 5.9 & S15 \\
& & SD 52 & SD 2861 & SD 428 & SD 0.6 & SD 6 & NA \\
\hline
\end{tabular}

\subsubsection{Trailing Call}

This is an advertisement call that also maintains inter-individual spacing (Figure 7A Supplemental Sound S13). This call uses a frequency range that is below the song of katydids from 220 to $6195 \mathrm{~Hz}$, with a peak frequency at $1594 \mathrm{~Hz}$. Average length of the call is $3.2 \mathrm{~s} .42 \%$ of the calls received a reply from another Otolemur.

\subsubsection{Cluster Squawk}

This is used as a contact call together with the trailing call, or as a mild alarm call (Figure 7B Supplemental Sound S14). In this analysis, subunits of squawk calls were analysed together if emitted together, thus the name cluster squawk. MLR classified $76.6 \%$ of the calls correctly. As a warning call it does not elicit escape behaviour in conspecifics but brings their attention. It may be used by itself, or in combinations of 2-4 units. As a warning call it can also be repeated hundreds of times. Average frequency range of the cluster squawk is $4258 \mathrm{~Hz}$ (SD 1938). The trailing call differs from the cluster squawk both in duration and frequency range (Figure 8).

\subsubsection{Behavioural Observations}

Otolemurs are commonly seen and heard in the rural areas in the Taita Hills, and especially in and around the Ngangao Forest. In the Taita Hills, Otolemurs mostly live as bonded pairs. The pairs have their own core area, where they are always found in the evenings and in the mornings, usually together 
in the same tree. Individuals forage alone, but they keep contact with each other by using trailing calls. Otolemur individuals vary considerably in colour, size, and behaviour. For example, individuals may have either a dark or a white tail. This variability allowed us to identify individual animals that we observed frequently.

\subsection{Characterization of Paragalago Vocalizations}

Paragalagos are mostly located in the forest by their vocalizations. Long-range loud calls that Paragalagos use in the Taita Hills are the incremental contact call and the warning/mobbing calls chatter, chirrup, and yap (Figures 9 and 10, Table 4, Supplemental Data S1). These warning/mobbing calls are used in situations when a group is alarmed by a potential predator. The group is always calling together, although one animal may continue longer than the others do. Table 4 contains more information about the calls. Paragalagos also use 'buzz' calls in the Taita Hills. We also recorded very quiet and variable social calls that are used when the animals are in close proximity to each other; unfortunately, the volume of these vocalizations was too low to allow recording and thus in-depth analysis.

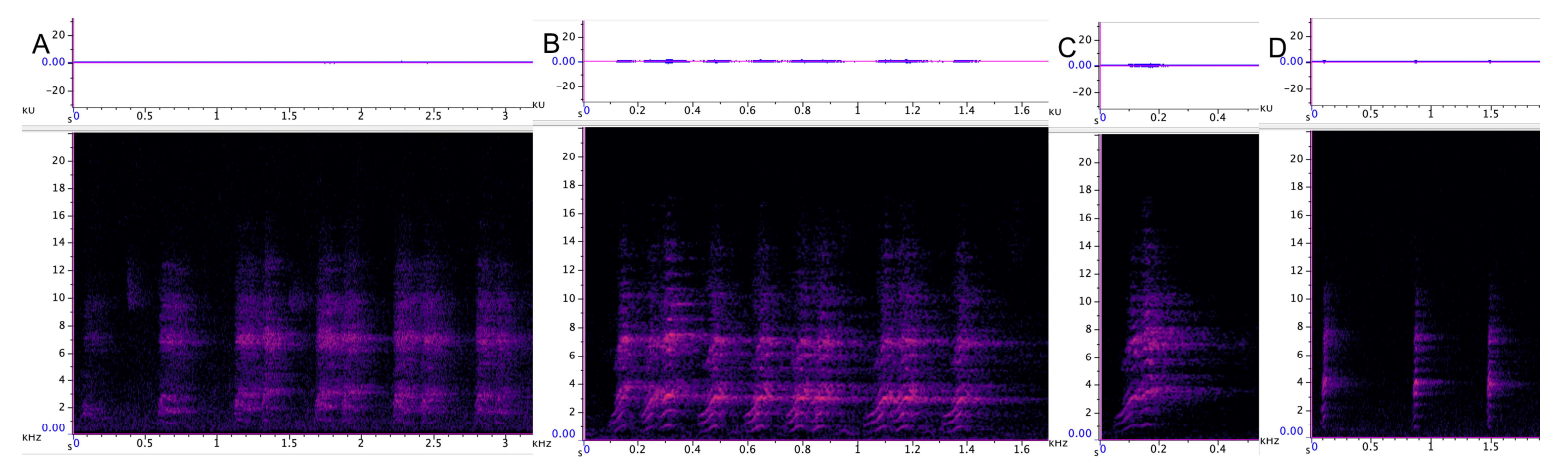

Figure 9. Paragalago calls (upper images: waveform, lower images: spectrogram). (A) Incremental call is used as a contact call and for maintaining inter-individual spacing during the night (Sound S15). It is used in the group assembly chorus in the morning and, less intensely, in the evenings. The call tends to grow incrementally towards the end. (B) Chatter is a mobbing call, used repeatedly with other mobbing calls chirrup and yap, usually in groups (Sound S16). (C) Chirrup is a mobbing call, and a single unit of chatter (Sound S17). It is used together with other mobbing calls, chatter and yap. (D) Yap is mobbing call and may be repeated hundreds of times with other mobbing calls, especially when the animals are agitated (Sound S18).

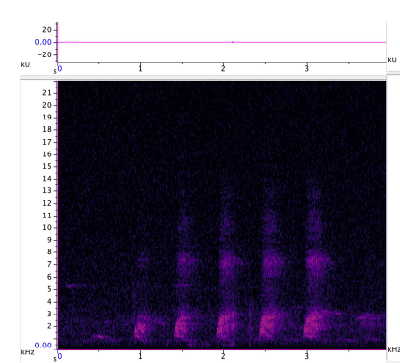

(A)

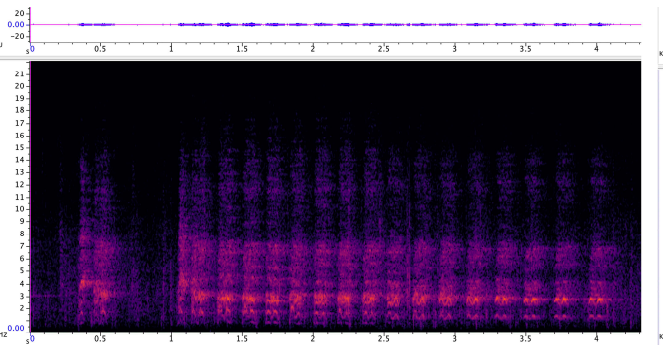

(B)

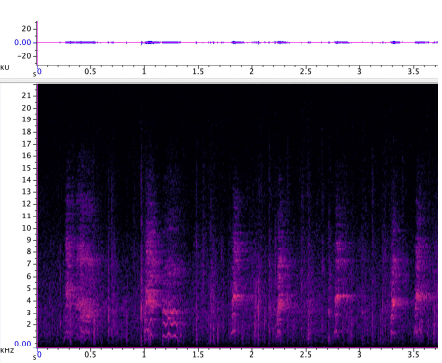

(C)

Figure 10. Paragalago calls from Mbololo Forest (upper images: waveform, lower images: spectrogram). (A) Screech is used as a contact call (Sound S19). (B) Chatter (Sound S20). (C) Chirrups and yaps (Sound S21). Mbololo Forest is very wet even during the dry season when it is not raining. This constant drizzle disturbs the recordings along with the almost constant chirping of katydids. 
Table 4. Vocal characteristics of Taita Hills Paragalago calls.

\begin{tabular}{|c|c|c|c|c|c|c|c|}
\hline Call Type. & $n$ & $\begin{array}{l}\text { Fundamental } \\
\text { Frequency } \mathrm{Hz}\end{array}$ & $\begin{array}{c}\text { Highest } \\
\text { Frequency } \mathrm{Hz}\end{array}$ & $\begin{array}{l}\text { Maximum } \\
\text { Frequency } \mathrm{Hz}\end{array}$ & Length s. & Energy $\mathrm{dB}$ & $\begin{array}{l}\text { Inter-Unit } \\
\text { Interval s. }\end{array}$ \\
\hline \multirow{2}{*}{ Incremental } & \multirow{2}{*}{31} & 974 & 13,734 & 4064 & 4.1 & 94 & \multirow[b]{2}{*}{ variable } \\
\hline & & SD 360 & SD 2085 & SD 2146 & SD 2.2 & SD 4.6 & \\
\hline \multirow{2}{*}{ Chatter } & \multirow[b]{2}{*}{43} & 533 & 15,680 & 3230 & 3.3 & 92.8 & \multirow{2}{*}{1.2 ( $n$ 77) } \\
\hline & & SD 390 & SD 2356 & SD 1218 & SD 1.5 & SD 5.6 & \\
\hline \multirow{2}{*}{ Chirrup } & \multirow{2}{*}{54} & 694 & 15,406 & 4144 & 0.29 & 90.4 & \multirow[b]{2}{*}{$0.6(n 94)$} \\
\hline & & SD 273 & SD 3124 & SD 1133 & SD 0.07 & SD 2.6 & \\
\hline \multirow{2}{*}{ Yap } & \multirow{2}{*}{45} & 1364 & 14,020 & 4365 & 0.1 & 83 & \multirow{2}{*}{$0.47(n$ 112) } \\
\hline & & SD 316 & SD 692 & SD 954 & SD 0.02 & SD 3.9 & \\
\hline
\end{tabular}

\subsubsection{Incremental Call}

This is a long-distance contact call (Figure 9A Supplemental Sound S15). The incremental call is used most frequently in the mornings as an assembly call. It is also used a few times in the evenings, when the animals leave their nests, and irregularly during the night for group coordination. About $50 \%$ of incremental calls receive a reply. Additional incremental calls from Ngangao Forest are available in the Supplemental Materials, spectrogram S22 and recording S23.

The incremental call is very variable. It contains 6-30 units that are emitted in pairs at the beginning of the call. Typically, combined units increase to three and even more than 12 units, thus the name incremental call. However, the strongest amplitude may be in the beginning, middle, or in the end. Maximum frequency is $4064 \mathrm{~Hz}$. Units may fluctuate with frequency modulation by going up in one unit and down in the next. An incremental call can also transform into chatter and become a mixed call. This may happen if the animal is alarmed, for example by the researcher's recorder and microphone. The percentage of correctly classified calls was low for incremental calls (41.9\%). All other incremental calls were classified as chatter by MLR.

\subsubsection{Chatter}

This is a warning or a mobbing call, typically used in combination with chirrups and yaps (Figure 9B Supplemental Sound S16). MLR classified 90.7\% of chatter calls correctly. Call duration varies from $1.6 \mathrm{~s}$ to $8.8 \mathrm{~s}$. Unit distance is $1.2 \mathrm{~s}$ in a mobbing sequence, and the call is repeated until the alarming situation is over. Several animals are usually calling together.

\subsubsection{Chirrup}

A warning call that is used in combination with chatter and yaps (Figure 9C Supplemental Sound S17). MLR classified correctly $92.6 \%$ of the calls. Redundancy is high with usually more than 200 chirrups in one calling bout.

\subsubsection{Yap}

This is a very short warning and mobbing call, which is used in combination with chatters and chirrups (Figure 9D Supplemental Sound S18). MLR classified 97.8\% of these calls correctly. Redundancy of the call is high, with hundreds of calls emitted when dwarf galagos are agitated. Yap is used more towards the end of mobbing sequences.

Graphical comparisons of Paragalago calls show that longer calls are incremental call and chatter, while chirrup and particularly yap are very short (Figure 11). Graphical comparison also shows how similar incremental call and chatter are in parameters used. However, calls are used in different contexts. Chatter is used with other warning and mobbing calls chirrup and yap with high repetition. 


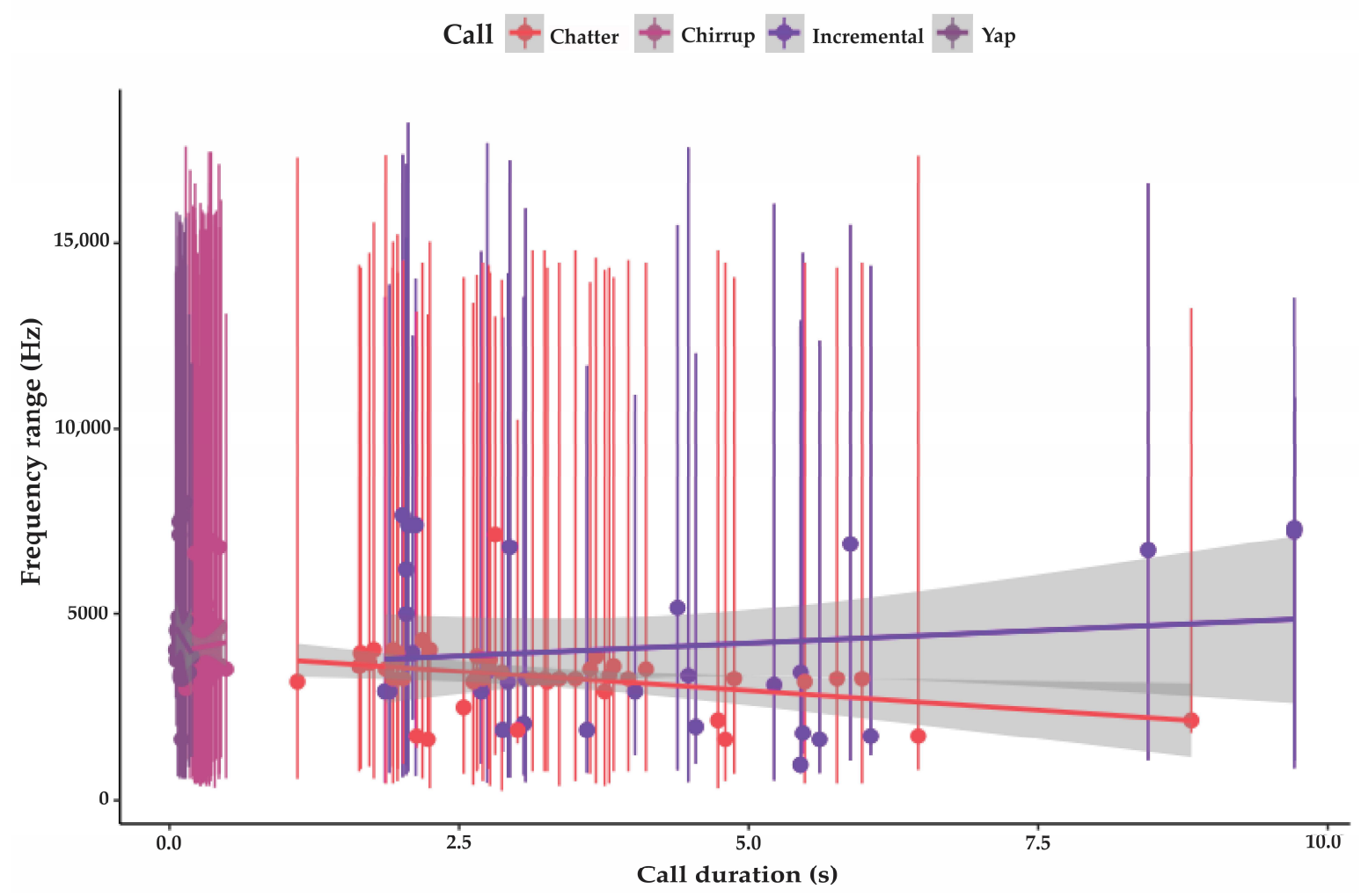

Figure 11. Graphical comparison of four Paragalago calls. The dots represent maximum frequencies. Incremental call and chatter are very similar in duration and frequency range, but are used in different contexts. The incremental call is used as a contact call and in group-calling bouts. Chatter is used when Paragalagos are agitated, typically combined with chirrups and yaps. Yap and chirrup are short warning calls, especially yap being very short.

\subsubsection{Behavioural Observations}

Paragalagos were most frequently observed hunting insects in the lower canopy of Ngangao Forest. They mostly climbed vertically on small trees with trunk diameters of $2-4 \mathrm{~cm}$ and moved to another tree by jumping. However, they use all forest strata, up to $50 \mathrm{~m}$ height. Animals forage alone but may meet and socialize during the night. Paragalagos in Ngangao are clearly social. We observed bouts of grooming behaviour and gatherings of a few individuals on almost every night of observation. They spend their days in tree hollows, in groups. In the morning, they group together after hearing an assembly call close to a nest site. The group assembles quickly, and the individuals all join into the morning incremental call chorus. After chorusing they may split into two groups [66].

\section{Discussion}

Our analyses of loud calls of Dendrohyrax, Otolemur, and Paragalago in the Taita Hills provide new insights into their taxonomic status. In the Taita Hills, Dendrohyraxes make a distinctive loud call, the strangled twack, the like of which has not been recorded elsewhere. Here, we characterized this call in detail, as well as another distinct call type, the hac (Figure 4). The recorded loud calls are distinctly different from those recorded from Dendrohyrax arboreus (Figure 12A Supplemental Sound S19) or Dendrohyrax validus (Figure 12B Supplemental Sound S20). [5,88]. However, similar calls have been previously recorded in East Usambara and West Usambara and Pare Mountains, and possibly also in Mt Kilimanjaro and Mt Meru [5,33]. Strangled thwacks are most likely advertisements of the social status of male Dendrohyrax, comparable to the snorts of rock hyrax males [89]. This type of call has only been recorded in the Taita Hills and the Usambara Mountains [5], which indicates that these animals may represent an as of yet undescribed taxon. 


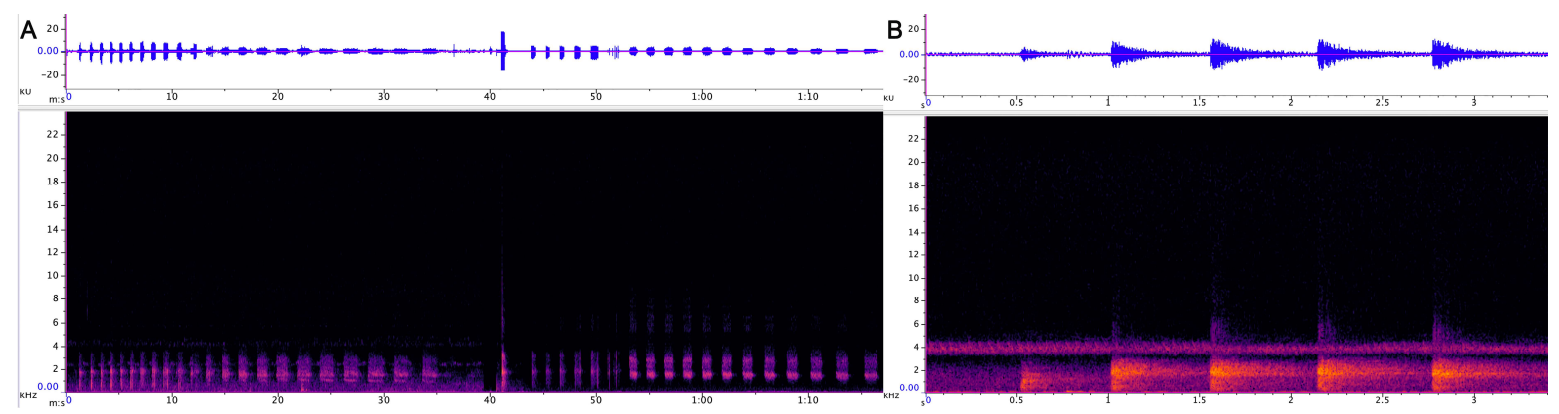

Figure 12. Dendrohyrax calls recorded from other parts of East Africa. (A) Dendrohyrax arboreus rattle screams recorded from Nairobi, Kenya, in 2000 by Andrew Perkin (Sound S24). (B) D. validus knocking sequence from recorded from Udzungwa Mountains, Tanzania, in 2001 by Thomas Butynski (Sound S25). Neither call is used by Dendrohyraxes in the Taita Hills.

The strangled thwack of Dendrohyrax is a very loud call with a large frequency range of over $16,000 \mathrm{~Hz}$. This call was never repeated for more than 20 times during one vocalization session, but the sequence often continued as a series of hac calls that have a smaller frequency range of about $9000 \mathrm{~Hz}$. Calling in sequences that last for minutes is energetically costly. This is especially true for a herbivorous mammal such as Dendrohyrax, which lives on an energy-poor diet of fibrous leaves and which presumably, like other hyraxes, has a low metabolic level $[23,24]$. Vocal turn-taking and counter calling is essential part of Dendrohyrax acoustic communication. Our recordings also suggest that Dendrohyraxes are adding variation and nonlinear noises to their calls. This may facilitate individual recognition and elicit responses from other individuals [90]. The active counter-calling of Dendrohyraxes in the Taita Hills suggests that their social life is more complex than previously thought [24].

In the Taita Hills, Dendrohyraxes occasionally sing, and while singing they use long tonal whistles and repeated syllables in tight, short, broadband pulses. One type of syllable is repeated 10-70 times, after which the animal switches to another type of syllable (Figure 6). To our knowledge, our recordings and descriptions of Dendrohyrax songs are the first from anywhere in Africa. Song structures have been previously described in the rock hyrax Procavia capensis [91-94]. Rock hyrax males use these songs to advertise their fitness to females. In Procavia capensis, only one in three of the adult males sing, these songs being individually different [92]. Songs of Procavia capensis [89,91,92] and Dendrohyrax in the Taita Hills have similarities in their syllables. Strictly harmonic songs are rare, and deterministic chaos is very common. More research is needed on these songs and their behavioural meaning.

Otolemur garnettii has an extensive vocal repertoire with 12 different call types [13,50]. Otolemurs in Taita Hills also have several different calls, but the only loud calls they use are the trailing call and the cluster squawk. The trailing call is a loud and long call that is used for advertising and for maintaining social distance. It begins loudly with several notes and then trails away [95]. The squawk call is shorter, and bark-like. It may be used as a counter-call with trailing calls, or as a mild alarm. The Taita Hills are situated near the transition zone between the ranges of two small-eared greater galago subspecies, Otolemur garnettii lasiotis and O. g. panganiensis [96]. We thus compared the trailing calls of O. g. panganiensis [13], O.g. lasiotis [11], and the Otolemurs from the Taita Hills (Table 5). Acoustic comparison confirms that the subspecies in the Taita Hills is O. g. lasiotis. The main difference between the calls of different subspecies is the peak frequency of the call, which in the Taita Hills is $1593 \mathrm{~Hz}$, whereas peak frequency is $819 \mathrm{~Hz}$ in O. g. panganiensis and $1320 \mathrm{~Hz}$ in O. g. lasiotis. The peak frequency in O.g. lasiotis is much closer to the peak frequency found in the Taita Hills, and for all calls in the Taita Hills, the peak frequency was above $1200 \mathrm{~Hz}$. 
Table 5. Vocal characteristics of previously recorded O. garnettii subspecies, Otolemur panganiensis and O. lasiotis calls, and Otolemur calls now recorded from the Taita Hills.

\begin{tabular}{cccccccc}
\hline & $\boldsymbol{n}$ & $\begin{array}{c}\text { Mean Call } \\
\text { Length s }\end{array}$ & $\begin{array}{c}\text { Call } \\
\text { Range s }\end{array}$ & $\begin{array}{c}\text { Mean Number } \\
\text { of Units }\end{array}$ & $\begin{array}{c}\text { Range Number } \\
\text { of Units }\end{array}$ & $\begin{array}{c}\text { Low } \\
\text { Frequency Hz }\end{array}$ & $\begin{array}{c}\text { Maximum } \\
\text { Frequency Hz }\end{array}$ \\
\hline $\begin{array}{c}\text { O. g. panganiensis } \\
\text { (Bettridge et al. 2019) }\end{array}$ & 226 & 3.08 & $0.9-6.43$ & 7.7 & $3-15$ & 533 & 819 \\
\hline $\begin{array}{c}\text { O. lasiotis } \\
\text { Bettridge et al. 2019) }\end{array}$ & 10 & 2.42 & 0.87 & 5.6 & $4-8$ & 200 & 1320 \\
\hline $\begin{array}{c}\text { Otolemur } \\
\text { Taita Hills (this study) }\end{array}$ & 78 & 3.2 & $0.35-3.97$ & 7.3 & $5-12$ & 227 & 1593 \\
\hline
\end{tabular}

O. garnettii is believed to be mainly solitary [52]. However, in the Taita Hills, Otolemur appears to live mostly in pairs. In Kwa Kuchinja, Tanzania, O. garnettii has also been observed to sleep in pairs or even in groups of four [13]. It is possible that this species can alter its social behaviour according to environmental conditions.

There are clear behavioural differences between Paragalago individuals in the Ngangao and the Mbololo Forests. In Ngangao, the animals are either indifferent or inquisitive towards humans, sometimes even displaying mobbing behaviour towards observers. The animals in Mbololo are very shy and difficult to observe or photograph. In Mbololo, Paragalago advertisement call is a curtailed version that resembles the advertisement call of $P$. orinus. We never heard Paragalago use the incremental call in Mbololo. A possible explanation may be that the advertisement call of the geographically isolated Paragalago species from Mbololo has diverged over time from the more typical call of P. cocos. Alternatively, the Mbololo Forest Paragalago is indeed P. orinus.

Paragalago call recordings from Ngangao were listened to by several primatologists and identified unanimously as P. cocos [66]. Also, comparison of acoustic parameters demonstrates that Paragalago cocos (recorded from Diani, Kenya) [12] and the Paragalago in the Taita Hills use the same acoustic range in all parameters (Table 6). However, P. cocos lives in the coastal areas of Kenya, and in the lowlands along the Tana River. The closest $P$. cocos populations live at a distance of $160 \mathrm{~km}$ from the Taita Hills. The intervening area between these areas and the Taita Hills consists of dry, mostly treeless savannah and shrub-land, which is presumably impossible for forest-living dwarf galagos to cross. Altitudinally, P. cocos ranges up to at least $350 \mathrm{~m}$ a.s.l. on the northern slopes of the East Usambara Mountains in Tanzania [12,97]. P. cocos lives in dry, mixed, coastal forests with tree heights of 15-20 m [52]. In the Taita Hills, the Paragalagos live at altitudes between 1550-1900 m a.s.l., in the most pristine parts of an indigenous moist montane forest where the upper canopy reaches $50 \mathrm{~m}$. The dusk chorus of coastal P. cocos is distinct whereas the morning chorus is modest [12]. In contrast, in the Taita Hills, the morning chorus is loud and the evening chorus modest.

Table 6. Comparison of incremental calls recorded from the Taita Hills in this study and those of Paragalago cocos recorded from Diani, Kenya (Butynski et al., 2006).

\begin{tabular}{ccc}
\hline & Paragalago, Taita Hills & Paragalago cocos, Diani \\
\hline Fundamental frequency & $800-1200 \mathrm{~Hz}$ & $800-1200 \mathrm{~Hz}$ \\
Frequency range & $680-14,500 \mathrm{~Hz}$ & $650-11,150$ \\
Harmonics visible & $9000 \mathrm{~Hz}$ & 9300 (10th of 11th harmonic) \\
Duration & $3.55 \mathrm{~s}$ range 1.9-9.7 s & $4.3 \mathrm{~s}$ range 1.7-8.6 s \\
Mean number of phases & 6.6 (range 1-6) & 6 (range 1-11) \\
\hline
\end{tabular}

The closest relatives of P. cocos are the Tanzania coast dwarf galago Paragalago zanzibaricus and the Mosambique dwarf galago Paragalago granti [15]. Based on an analysis of vocalizations and DNA studies, Pozzi et al. [14] concluded that P. cocos and P. zanzibaricus represent two cryptic species that probably underwent speciation in the Late Pliocene, when their populations became isolated from 
each other by the fragmentation of the East African forests. Molecular analyses and comparisons with other Paragalago taxa are required to establishthe taxonomic identities of the Taita Hills Paragalagos.

The Paragalago population of Ngangao Forest is almost extinct with apparently no more than 10 individuals remaining. Several groups of Paragalago live scattered across the Mbololo Forest, but even there the species is not abundant. [66]

From a biogeographical point of view, it is interesting that Dendrohyrax, Otolemur, and Paragalago are all found also in the East Usambara Mountains in Tanzania, which are located only circa $160 \mathrm{~km}$ south of the Taita Hills. Otolemur and Paragalago are also known from Diani, Kenya, $170 \mathrm{~km}$ southeast of the Taita Hills. The remaining forests covering the Eastern Arc Mountains are home to a mammalian fauna with a high level of endemism [38,39,72,98]. Many of these Eastern Arc Mountain endemics or near-endemics are forest specialists that have poor abilities to disperse across extensive distances of non-forested habitat (e.g., $[99,100])$. Some taxa may be considered 'relicts', i.e., they represent old inhabitants of the area that have subsequently been replaced in the surrounding areas by later-arriving related taxa. Kingdon [38,39] suggested that Dendrohyrax validus, in particular, represents such a case, and that its current restricted distribution in eastern Africa is a consequence of having been outcompeted by its ecologically similar relative Dendrohyrax arboreus.

\section{Conclusions}

For the study of nocturnal arboreal mammals of cryptic habits and appearance, call analysis is one of the most effective research methods. In this report, we characterized and analysed calls of three very poorly known nocturnal mammals from East Africa. The results provide insights into identifying and monitoring these animals, and are also taxonomic tools that can be used to compare the Taita Hills animals with animals from other populations. The Dendrohyrax in the Taita Hills is probably an undescribed taxon, judged by its distinct loud calls that differ from those of tree hyraxes elsewhere. Its complex calling strategy implies that its social behaviour may be equally complex. Molecular, morphological, and behavioural studies are urgently needed to clarify the taxonomy of Dendrohyrax species, as their populations are currently diminishing across Africa. Our acoustic comparisons confirm that the O. garnettii subspecies in the Taita Hills is O. g. lasiotis. Our research suggests that the Paragalago population in the Ngangao Forest represents P. cocos, which has become isolated from other populations of this species. The taxonomic identity of the Paragalago population in Mbololo Forest remains an open question. It is of utmost importance and urgency that these elusive animals and their shrinking habitats receive both adequate protection and further study.

Supplementary Materials: The following data are available online at http://www.mdpi.com/1424-2818/12/ 12/473/s1, Data S1: Vocalizations of nocturnal mammals in the Taita Hills. Raw data of the analysed calls. Figure S2: Data exploration (A) Collinearity nine covariates (B) Collinearity three covariates (C) Cook's distance (D) Cleveland dot plot call duration in different calls (E) Cleveland dot plot maximum frequency of different calls (F) Maximum entropy of different calls. Data exploration was done according to the procedure described by Zuur et al. (2010). Sound S3: Dendrohyrax strangled thwack. Call begins with a twist at $7360 \mathrm{~Hz}$, rises to $10,700 \mathrm{~Hz}$, sinks to $6100 \mathrm{~Hz}$, rises again up to 8200 , and then sinks to $2100 \mathrm{~Hz}$. This strangled twist continues for $0.52 \mathrm{~s}$. Lower part of the call, "foot", has a fundamental frequency with first harmonic in $200 \mathrm{~Hz}$, six harmonics are visible in the spectrogram, duration of the "foot" part is $0.08 \mathrm{~s}$. Call has noisy elements at all stages of the call, rising up to $18,500 \mathrm{~Hz}$. Sound S4: Dendrohyrax strangled thwack sequence. Interunit distance in the sequence is 1.3-2.4 s. Sound S5: Dendrohyrax hac. Call has frequency modulated part between 450 and $3600 \mathrm{~Hz}$; however, noisy parts rise up to $13,300 \mathrm{~Hz}$ and noise forms about half of the call. Duration of the call is $0.46 \mathrm{~s}$, with noise continuing for $0.3 \mathrm{~s}$. Sound S6: Dendrohyrax hac sequence. In this sequence, interunit distance is $0.7-1.4 \mathrm{~s}$. Sound S7: Dendrohyrax wheeze thwack. Twist of strangled thwack is longer. Strongest amplitude of the call follows curve from $3400 \mathrm{~Hz}$ to $2700 \mathrm{~Hz}$, and $2300 \mathrm{~Hz}$ and finishes in 4700 . Lowest "foot" part of strangled thwack is almost invisible. Fundamental frequency is visible in 150 on the foot part and highest frequency rises up to 19,600 . From $5000 \mathrm{~Hz}$ upwards call is noise. Call duration $0.78 \mathrm{~s}$. Sound S8: Dendrohyrax double thwack. Here strangled thwack is followed immediately by smaller thwack. Fundamental frequency $280 \mathrm{~Hz}$, highest noise frequency up to 18,600 , strongest amplitude travels with the twist if first subunit from $5100 \mathrm{~Hz}$ to $3600 \mathrm{~Hz}$, up to $5500 \mathrm{~Hz}$ and lowers down to $1800 \mathrm{~Hz}$. In second subunit twist lowers from $4150 \mathrm{~Hz}$ to $1900 \mathrm{~Hz}$. Duration of the total call $0.95 \mathrm{~s}$, first unit 0.42 and second unit 0.25 . Sound S9: Dendrohyrax double hac. Like double thwack call, it may be used by the same individual. Second unit has stronger amplitude and twist that travels from $3850 \mathrm{~Hz}$ to $4400 \mathrm{~Hz}$ and lowers to $1900 \mathrm{~Hz}$. This twist has two harmonics. Fundamental frequency is $400 \mathrm{~Hz}$, highest frequency in 
first unit is 10,300 . Total duration of the call is $0.98 \mathrm{~s}$, first unit is $0.24 \mathrm{~s}$, and second unit is $0.55 \mathrm{~s}$. Sound S10: Dendrohyrax hac with four subunits. Fundamental frequency of the call is $250 \mathrm{~Hz}$, high frequency $9600 \mathrm{~Hz}$, this is only noise above 3400 . Duration of the call is $0.7 \mathrm{~s}$, and duration of subunits 0.03 . Sound S11: Dendrohyrax song A-C. (A) Cracle has fundamental frequency 1900-2500 Hz, highest frequency 7300-14,900 Hz. Total duration is $1.5 \mathrm{~s}$, duration of subunits $0.08-0.15 \mathrm{~s}$. Peak frequency is $31003800 \mathrm{~Hz}$. (B) Rachet has subunit with duration of $0.05-0.09 \mathrm{~s}$. Fundamental frequency $2200-2400 \mathrm{~Hz}$. Highest frequency 6000-6700 Hz. Vague peak frequency is from 2300 to $3900 \mathrm{~Hz}$. Call has lower amplitude and intensity than cracle. (C) Wheeze has fundamental frequency $2000-2500 \mathrm{~Hz}$, high frequency 17,200-18,000 Hz. Peak frequency 3200-46,700 Hz. Duration of one wheeze is 1-1.4 s. Sound S12: Dendrohyrax song D-E. (D) Chuck has fundamental frequency between 400 and $1500 \mathrm{~Hz}$, highest frequency is $13,500-14,000 \mathrm{~Hz}$. Total duration $5.4 \mathrm{~s}$. Duration of each subunits is $0.28-0.49 \mathrm{~s}$. (E) Chirp has fundamental frequency $2200-2500 \mathrm{~Hz}$, and high frequency $9600 \mathrm{~Hz}$ with noise rising up to 14,000 . Peak frequency $3000-4500 \mathrm{~Hz}$. Total duration is $3 \mathrm{~s}$, unit duration varies between 0.16 and $0.25 \mathrm{~s}$. Sound S13: Otolemur trailing call has fundamental frequency $280-440 \mathrm{~Hz}$ and highest frequency around $3800 \mathrm{~Hz}$, noisy parts reaching $6500 \mathrm{~Hz}$. Peak frequency $1100-1550 \mathrm{~Hz}$. Four harmonics are visible up to $1700 \mathrm{~Hz}$. Call duration is $3.38 \mathrm{~s}$, unit duration is $0.29 \mathrm{~s}$ (first) to $0.16 \mathrm{~s}$ (last). Sound S14: Otolemur cluster squawk has fundamental frequency $630 \mathrm{~Hz}$. Highest frequency with harmonics $5900 \mathrm{~Hz}$. Peak frequency 1550-2300 Hz. Duration of the call is $1.39 \mathrm{~s}$, unit length $0.39-0.29 \mathrm{~s}$. Sound S15: Paragalago incremental call has fundamental frequency 750-950 Hz, highest visible frequency 12,900 Hz. Peak frequency $7062 \mathrm{~Hz}$. Call has six phases, units per phase are from one to two. Duration of the call is $3.05 \mathrm{~s}$. Sound S16: Paragalago chatter has fundamental frequency $580-710 \mathrm{~Hz}$, highest visible frequency around 14,000 Hz. Peak frequency $3000 \mathrm{~Hz}$. Some harmonics are visible up to $12,700 \mathrm{~Hz}$. Call duration is $1.4 \mathrm{~s}$, this call has seven subunits $0.06-0.15 \mathrm{~s}$ long. Sound S17: Paragalago chirrup has fundamental frequency $550 \mathrm{~Hz}$, highest frequency 16,700, peak frequency $3500 \mathrm{~Hz}$. Nine harmonics are visible, up to around $9900 \mathrm{~Hz}$. Call duration is $0.34 \mathrm{~s}$. Sound S18: Paragalago yap has fundamental frequency $800-900 \mathrm{~Hz}$, and highest frequency around 10,000 Hz. Peak frequency 3900-4050 Hz. 13 harmonics are visible in the second call. Call duration is 0.09-0.23 s. Sound 19: Paragalago screech from Mbololo Forest. Sound S20: Paragalago chatter from Mbololo Forest. Sound 21: Paragalago chirrups and yaps from Mbololo Forest. Spectrogram S22: Paragalago incremental calls from Ngangao Forest. Sound S23 Recording of Paragalago incremental calls from Ngangao Forest. Sound S24: Dendrohyrax arboreus rattle scream (Perkin 2000). Sound S25: Dendrohyrax validus knocking sequence (Butynski 2001).

Author Contributions: H.R., J.R. and S.B. conceived the idea; H.R. and J.R. performed the fieldwork, collected the data, designed the methodology with S.B., conducted the research and analysed the data with S.B. H.R., H.P. and J.R. wrote the paper, P.P. and S.B. edited the paper. H.R. and created the visualizations and P.P cartography. P.P. and J.R. contributed resources and project administration. J.R., P.P. and S.B. supervised the research. All authors have read and agreed to the published version of the manuscript.

Funding: Funding for PP from the Academy of Finland (decision number 3186459 for the project "Environmental sensing of ecosystem services for developing a climate-smart landscape framework to improve food security in East Africa" is acknowledged, as well as financial support from the University of Helsinki.

Acknowledgments: We would like to thank the staff of the University of Helsinki's Taita Research Station for the logistical support during the fieldwork. In addition, we acknowledge Benson Mwachakola for field assistance. We are also grateful to Thomas Butynski for valuable support at all stages of the research. We thank Andrew Perkin and Thomas Butynski for Dendrohyrax arboreus and D. validus recordings. Research permit from Kenya Forest Service KFS/TTFS/7/1/4/Vol.II/14 and Research permit from the National Council for Science and Technology of Kenya NCST/RCD/17/012/33 are gratefully acknowledged. Three anonymous referees provided insightful comments that greatly improved the manuscript.

Conflicts of Interest: The authors declare no conflict of interest.

\section{References}

1. Snowden, C. Is speech special? Lessons from New World primates. In New World Primates: Ecology, Evolution and Behavior; Kinzey, W.G., Ed.; Aldine De Gruyter: New York, NY, USA, 1997; pp. 75-94.

2. Braune, P.; Schmidt, S.; Zimmermann, E. Acoustic divergence in the communication of cryptic species of nocturnal primates (Microcebus ssp.). BMC Biol. 2008, 6, 19. [CrossRef] [PubMed]

3. Gursky, S.; Nekaris, K.A.I. Primate communication: Ecology, evolution and conservation. Folia Primatol. 2019, 90, 273-278. [CrossRef] [PubMed]

4. Masters, J. Speciation in the greater galagos (Prosimii: Galaginae): Review and synthesis. Biol. J. Linn. Soc. 1988, 34, 149-174. [CrossRef]

5. Roberts, D. Geographic Variation in the Loud Calls of Tree Hyrax—Dendrohyrax validus (True 1890) in the Eastern Arc Mountains, East Africa: Taxonomic and Conservation Implications. Master's Thesis, University of Reading, Reading, UK, 2001.

6. Paterson, H.E.H. The recognition concept of species. In Species and Speciation; Vrba, E.S., Ed.; Transvaal Museum Monograph No. 4: Pretoria, South Africa, 1985; pp. 21-29. 
7. Masters, J.C. Speciation in the lesser galagos. Folia Primatol. 1998, 69 (Suppl. 1), 357-370. [CrossRef]

8. Masters, J.C.; Boniotto, M.; Crovella, S.; Roos, C.; Pozzi, L.; Delpero, M. Phylogenetic relationships among the Lorisoidea as indicated by craniodental morphology and mitochondrial sequence data. Am. J. Primatol. 2007, 69, 6-15. [CrossRef]

9. Bearder, S.K.; Honess, P.E.; Ambrose, L. Species Diversity Among Galagos with Special Reference to Mate Recognition. In Creatures of the Dark: The Nocturnal Prosimians; Alterman, L., Doyle, G.A., Izard, M.K., Eds.; Springer US: Boston, MA, USA, 1995; pp. 331-352. ISBN 978-1-4419-3250-1.

10. Bearder, S.K. Physical and social diversity among nocturnal primates: A new view based on long term research. Primates 1999, 40, 267-282. [CrossRef]

11. Masters, J.C. Loud calls of Galago crassicaudatus and G. garnettii and their relation to habitat structure. Primates 1991, 32, 153-167. [CrossRef]

12. Butynski, T.M.; de Jong, Y.A.; Perkin, A.W.; Bearder, S.K.; Honess, P.E. Taxonomy, distribution, and conservation status of three species of dwarf galagos (Galagoides) in eastern Africa. Primate Conserv. 2006, 21, 63-79. [CrossRef]

13. Bettridge, C.M.; Kenworthy, S.P.; Butynski, T.M.; de Jong, Y.A.; de Kort, S.R. Vocal repertoire and intraspecific variation within two loud calls of the small-eared greater galago (Otolemur garnettii) in Tanzania and Kenya. Folia Primatol. 2019, 90, 319-335. [CrossRef]

14. Pozzi, L.; Disotell, T.R.; Bearder, S.K.; Karlsson, J.; Perkin, A.; Gamba, M. Species boundaries within morphologically cryptic galagos: Evidence from acoustic and genetic data. Folia Primatol. 2019, 90, 279-299. [CrossRef]

15. Masters, J.C.; Génin, F.; Couette, S.; Groves, C.P.; Nash, S.D.; Delpero, M.; Pozzi, L. A new genus for the eastern dwarf galagos (Primates: Galagidae). Zool. J. Linn. Soc. 2017, 181, 229-241. [CrossRef]

16. Butynski, T.M.; Chapman, C.A.; Chapman, L.J.; Weary, D.M. Use of male blue monkey "pyow" calls for long-term individual identification. Am. J. Primatol. 1992, 28, 183-189. [CrossRef] [PubMed]

17. Ey, E.; Fischer, J. The "Acoustic Adaptation Hypothesis"-A review of the evidence from birds, anurans and mammals. Bioacoustics 2009, 19, 21-48. [CrossRef]

18. Bradbury, J.W.; Vehrencamp, S.L. Principles of Animal Communication, 2nd ed.; Sinauer Associates: Sunderland, MA, USA, 2011; ISBN 978-0-87893-045-6.

19. Patricelli, G.L.; Hebets, E.A. New dimensions in animal communication: The case for complexity. Curr. Opin. Behav. Sci. 2016, 12, 80-89. [CrossRef]

20. Gustison, M.L.; le Roux, A.; Bergman, T.J. Derived vocalizations of geladas (Theropithecus gelada) and the evolution of vocal complexity in primates. Phil. Trans. Roy. Soc. B 2012, 367, 1847-1859. [CrossRef]

21. Fischer, J.; Wadewitz, P.; Hammerschmidt, K. Structural variability and communicative complexity in acoustic communication. Anim. Behav. 2017, 134, 229-237. [CrossRef]

22. Grubb, P. English common names for subspecies and species of African primates. Primate Conserv. 2006, 20, 65-73. [CrossRef]

23. Kundaeli, J.N. Distribution of tree hyrax (Dendrohyrax validus validus True) on Mt Kilimanjaro, Tanzania. Afr. J. Ecol. 1976, 14, 253-264. [CrossRef]

24. Maloiy, G.M.O.; Eley, R.M. The Hyrax; R.M. Eley: Nairobi, Kenya, 1992; ISBN 978-92-9055-702-9.

25. Gaylard, A.; Kerley, G.I.H. Habitat assessment for a rare, arboreal forest mammal, the tree hyrax Dendrohyrax arboreus. Afr. J. Ecol. 2001, 39, 205-212. [CrossRef]

26. Fey, V. A note on the behavior of the tree hyrax. East Afr. Geogr. Rev. 1960, 23, 244-246.

27. Rudnai, J. Activity cycle and space utilization in captive Dendrohyrax arboreus. S. Afr. J. Zool. 1984, 19, 124-128. [CrossRef]

28. Milner, J. Relationships between the forest dwelling people of South-West Mau and tree hyrax Dendrohyrax arboreus. J. East Afr. Nat. Hist. 1994, 83, 17-29. [CrossRef]

29. Milner, J.M.; Harris, S. Activity patterns and feeding behaviour of the tree hyrax, Dendrohyrax arboreus, in the Parc National des Volcans, Rwanda. Afr. J. Ecol. 1999, 37, 267-280. [CrossRef]

30. Richard, P. Notes sur la biologie du daman des arbes (Dendrohyrax dorsalis). Biol. Gabonica 1964, 1, 73-84.

31. Rahm, U. Notes sur le cri du Dendrohyrax dorsalis (Hyracoidea). Mammalia 1969, 33, 68-79. [CrossRef]

32. Djossa, B.A.; Zachee, B.A.; Sinsin, B.A. Activity patterns and habitat use of the western tree hyrax (Dendrohyrax dorsalis), within forest patches and implications for conservation. Ecotropica 2012, 2012, 65-72.

33. Roberts, D.; Topp-Jørgensen, E.; Moyer, D.C. Dendrohyrax validus Eastern tree hyrax. In Mammals of Africa; Kingdon, J., Ed.; Bloomsbury: London, UK, 2013; Volume I, pp. 158-161. 
34. Hahn, H. Die Familie der Procaviidae. Zeitschr. Säugetierk. 1934, 9, 207-358.

35. Hahn, H. Baumschliefer, Buschschliefer, Klippschliefer; Die Neue Brehm-Bücherei, Heft 246; A. Ziemsen Verlag: Wittenberg Lutherstadt, German Democratic Republic, 1959.

36. Jones, C. Dendrohyrax dorsalis. Mamm. Species 1978, 113, 1-4. [CrossRef]

37. Hoeck, H. Some thoughts on the distribution of the tree hyraxes (genus Dendrohyrax) in northern Tanzania. Afrotherian Conserv. 2017, 13, 47-49.

38. Kingdon, J. Where have the colonists come from? A zoogeographical examination of some mammalian isolates in eastern Africa. Afr. J. Ecol. 1981, 19, 115-124. [CrossRef]

39. Kingdon, J. Island Africa: The Evolution of Africa's Rare Animals and Plants; Collins: London, UK, 1990; ISBN 978-0-00-219914-8.

40. Seibt, U.; Hoeck, H.; Wickler, W. Dendrohyrax validus True, 1890 in Kenya. Zeitschr. Säugetierk. 1977, 42, $115-118$.

41. Bloomer, P. Extant hyrax diversity is vastly underestimated. Afrotherian Conserv. 2009, 7, 11-16.

42. Bearder, S.K.; Oates, J.F.; Dowsett-Lemaire, F.; Dowsett, R. Evidence of an undescribed form of tree hyrax in the forests of western Nigeria and the Dahomey Gap. Afrotherian Conserv. 2015, 11, 2-5.

43. True, F.W. Description of Two New Species of Mammals from Mt. Kilima-Njaro, East Africa; US Government Printing Office: Washington, DC, USA, 1890; Volume 13, pp. 227-229. [CrossRef]

44. True, F.W. An Annotated Catalogue of the Mammals Ccollected by Dr. W. L. Abbott in the Kilimanjaro Region, East Africa; US Government Printing Office: Washington, DC, USA, 1892; Volume 15, pp. 445-480.

45. Matschie, P. Über anscheinend neue afrikanische Säugethiere (Leimacomys n. g.). Sitz. Ber. Ges. Nat. Freunde Berlin 1893, 1893, 107-114.

46. Brauer, A. Neue Procaviiden. Sitz. Ber. Ges. Nat. Freunde Berlin 1917, 1917, 294-303.

47. Mollison, T. Dendrohyrax nova species, aff. D. neumanni. Zool. Anz. 1905, 24, 417-424.

48. Beentje, H. An ecological and floristical study of the forests of the Taita Hills, Kenya. Utafiti 1988, 1, $23-66$.

49. Bytebyer, B. Taita Hills Biodiversity Project Report; National Museums of Kenya: Nairobi, Kenya, 2001.

50. Nash, L.T.; Harcourt, C.S. Social organization of galagos in Kenyan coastal forests: II. Galago garnettii. Am. J. Primatol. 1986, 10, 357-369. [CrossRef]

51. Harcourt, C.S.; Perkin, A.W. Otolemur garnettii Small-eared greater galago. In Mammals of Africa; Kingdon, J., Ed.; Bloomsbury: London, UK, 2013; Volume II, pp. 413-416.

52. Harcourt, C.S.; Perkin, A.W. Galagoides cocos Kenya coast dwarf galago (Diani dwarf galago). In Mammals of Africa; Kingdon, J., Ed.; Bloomsbury: London, UK, 2013; Volume II, pp. 457-459.

53. Masters, J. Geographic distributions of karyotypes and morphotypes within the greater galagines. Folia Primatol. 1986, 46, 127-141. [CrossRef]

54. Nash, L.T.; Bearder, S.K.; Olson, T.R. Synopsis of Galago species characteristics. Int. J. Primatol. 1989, 10, 57-80. [CrossRef]

55. Anderson, M.J. The use of hand morphology in the taxonomy of galagos. Primates 1999, 40, 469-478. [CrossRef]

56. Anderson, M.J.; Ambrose, L.; Bearder, S.K.; Dixson, A.F.; Pullen, S. Intraspecific variation in the vocalizations and hand pad morphology of southern lesser bush babies (Galago moholi): A comparison with G. senegalensis. Int. J. Primatol. 2000, 21, 537-555. [CrossRef]

57. DelPero, M.; Masters, J.C.; Zuccon, D.; Cervella, P.; Crovella, S.; Ardito, G. Mitochondrial sequences as indicators of generic classification in bush babies. Int. J. Primatol. 2000, 21, 889-904. [CrossRef]

58. Stiner, E.; Turmelle, A. Galagid taxonomy and the placement of the needle-clawed galago (Euoticus): Based on cytochrome b, 12S and 16S partial sequences. Afr. Primates 2002, 6, 3-10.

59. Kingdon, J. The Kingdon Field Guide to African Mammals; Natural World Academic Press: London, UK, 1997; ISBN 978-0-69111-692-1.

60. Groves, C.P. Primate Taxonomy; Smithsonian Institution Press: Washington, DC, USA, 2001; ISBN 978-1-56098-872-4.

61. Olson, T. Systematics and zoogeography of the greater galagos. Am. J. Phys. Anthropol. 1981, 54, 259. [CrossRef]

62. Grubb, P.; Butynski, T.M.; Oates, J.F.; Bearder, S.K.; Disotell, T.R.; Groves, C.P.; Struhsaker, T.T. Assessment of the diversity of African primates. Int. J. Primatol. 2003, 24, 1301-1357. [CrossRef]

63. Pozzi, L.; Disotell, T.R.; Masters, J.C. A multilocus phylogeny reveals deep lineages within African galagids (Primates: Galagidae). BMC Evol. Biol. 2014, 14, 72. [CrossRef]

64. Pozzi, L.; Nekaris, K.A.-I.; Perkin, A.; Bearder, S.K.; Pimley, E.R.; Schulze, H.; Streicher, U.; Nadler, T.; Kitchener, A.; Zischler, H.; et al. Remarkable ancient divergences amongst neglected lorisiform primates. Zool. J. Linn. Soc. 2015, 175, 661-674. [CrossRef] 
65. Perkin, A.; Bearder, S.; Butynski, T.M.; Agwanda, B.; Bytebier, B. The Taita Mountain dwarf galago Galagoides sp: A new primate for Kenya. J. East Afr. Nat. Hist. 2002, 91, 1-13. [CrossRef]

66. Rosti, H.; Rikkinen, J.; Pellikka, P.; Bearder, S.; Mwang'ombe, J. Taita Mountain dwarf galago is extant in the Taita Hills of Kenya. Oryx 2020, 54, 152-153. [CrossRef]

67. Wagura, L. A Guide to Taita Hills: Unique Natural History; ABC: Nairobi, Kenya, 2014; ISBN 978-9966-074-61-4.

68. Pellikka, P.K.E.; Lötjönen, M.; Siljander, M.; Lens, L. Airborne remote sensing of spatiotemporal change (1955-2004) in indigenous and exotic forest cover in the Taita Hills, Kenya. Int. J. Appl. Earth Obs. Geoinf. 2009, 11, 221-232. [CrossRef]

69. Wilder, C.; Brooks, T.; Lens, L. Vegetation structure and composition of the Taita Hills forests. J. East Afr. Nat. Hist. 1998, 87, 181-187. [CrossRef]

70. Aerts, R.; Thijs, K.W.; Lehouck, V.; Beentje, H.; Bytebier, B.; Matthysen, E.; Gulinck, H.; Lens, L.; Muys, B. Woody plant communities of isolated Afromontane cloud forests in Taita Hills, Kenya. Plant Ecol. 2011, 212, 639-649. [CrossRef]

71. Malombe, I.; Matheka, K.W.; Pócs, T.; Patiño, J. Edge effect on epiphyllous bryophytes in Taita Hills fragmented afromontane forests. J. Bryol. 2016, 38, 33-46. [CrossRef]

72. Burgess, N.D.; Butynski, T.M.; Cordeiro, N.J.; Doggart, N.H.; Fjeldså, J.; Howell, K.M.; Kilahama, F.B.; Loader, S.P.; Lovett, J.C.; Mbilinyi, B.; et al. The biological importance of the Eastern Arc Mountains of Tanzania and Kenya. Biol. Conserv. 2007, 134, 209-231. [CrossRef]

73. Myers, N.; Mittermeier, R.A.; Mittermeier, C.G.; da Fonseca, G.A.B.; Kent, J. Biodiversity hotspots for conservation priorities. Nature 2000, 403, 853-858. [CrossRef]

74. Dimitrov, D.; Nogués-Bravo, D.; Scharff, N. Why do tropical mountains support exceptionally high biodiversity? The Eastern Arc Mountains and the drivers of Saintpaulia diversity. PLoS ONE 2012, 7, e48908. [CrossRef]

75. Gereau, R.E.; Cumberlidge, N.; Hemp, C.; Hochkirch, A.; Jones, T.; Kariuki, M.; Lange, C.N.; Loader, S.P.; Malonza, P.K.; Menegon, M.; et al. Globally threatened biodiversity of the Eastern Arc Mountains and coastal forests of Kenya and Tanzania. J. East Afr. Nat. Hist. 2016, 105, 115-201. [CrossRef]

76. Heiskanen, J.; Korhonen, L.; Hietanen, J.; Pellikka, P.K.E. Use of airborne lidar for estimating canopy gap fraction and leaf area index of tropical montane forests. Int. J. Remote Sens. 2015, 36, 2569-2583. [CrossRef]

77. Adhikari, H.; Heiskanen, J.; Siljander, M.; Maeda, E.; Heikinheimo, V.; KE Pellikka, P. Determinants of aboveground biomass across an Afromontane landscape mosaic in Kenya. Remote Sens. 2017, 9, 827. [CrossRef]

78. Himberg, N. Traditionally Protected Forests' Role within Transforming Natural Resource Management Regimes in Taita Hills, Kenya. Ph.D. Thesis, University of Helsinki, Helsinki, Finland, 2011. Department of Geosciences and Geography A 14. 1798-7911.

79. Teucher, M.; Schmitt, C.B.; Wiese, A.; Apfelbeck, B.; Maghenda, M.; Pellikka, P.; Lens, L.; Habel, J.C. Behind the fog: Forest degradation despite logging bans in an East African cloud forest. Global Ecol. Conserv. 2020, 22, e01024. [CrossRef]

80. Thijs, K.W.; Aerts, R.; Musila, W.; Siljander, M.; Matthysen, E.; Lens, L.; Pellikka, P.; Gulinck, H.; Muys, B. Potential tree species extinction, colonization and recruitment in Afromontane forest relicts. Basic Appl. Ecol. 2014, 15, 288-296. [CrossRef]

81. Thijs, K.W. Tree Community Dynamics and Ecosystem Function in a Tropical Landscape under Deforestation Pressure. Ph.D. Thesis, KU Leuven, Science, Engineering \& Technology, Leuven, Belgium, 2015.

82. Stam, Å.; Enroth, J.; Malombe, I.; Pellikka, P.; Rikkinen, J. Experimental transplants reveal strong environmental effects on the growth of non-vascular epiphytes in Afromontane forests. Biotropica 2017, 49, 862-870. [CrossRef]

83. Stam, Å.; Anttila, J.; Pellikka, P.; Rikkinen, J. Sensitivity of tropical pendant Bryophytes: Results from a translocation experiment along an elevation gradient. Ann. Bot. Fenn. 2020, 57, 71. [CrossRef]

84. Siljander, M.; Kuronen, T.; Johansson, T.; Munyao, M.N.; Pellikka, P.K.E. Primates on the farm-Spatial patterns of human-wildlife conflict in forest-agricultural landscape mosaic in Taita Hills, Kenya. Appl. Geogr. 2020, 117, 102185. [CrossRef]

85. Hemp, C.; Heller, K.-G.; Warchałowska-Śliwa, E.; Grzywacz, B.; Hemp, A. Biogeography, ecology, acoustics and chromosomes of East African Eurycorypha Stål species (Orthoptera, Phaneropterinae) with the description of new species. Org. Divers. Evol. 2013, 13, 373-395. [CrossRef] 
86. Heller, K.-G.; Hemp, C. Extremely divergent song types in the genus Aerotegmina Hemp (Orthoptera: Tettigoniidae: Hexacentrinae) and the description of a new species from the Eastern Arc Mountains of Tanzania (East Africa). Bioacoustics 2019, 28, 269-285. [CrossRef]

87. Zuur, A.F.; Ieno, E.N.; Elphick, C.S. A protocol for data exploration to avoid common statistical problems: Data exploration. Methods Ecol. Evol. 2010, 1, 3-14. [CrossRef]

88. Roberts, D. A Preliminary Investigation of the Taxonomic Implications of the Loud Calls of Dendrohyrax (Hyracoidea, Procaviidae) in Africa. Master's Thesis, Oxford Brookes University, Oxford, UK, 1999.

89. Koren, L.; Geffen, E. Complex call in male rock hyrax (Procavia capensis): A multi-information distributing channel. Behav. Ecol. Sociobiol. 2009, 63, 581-590. [CrossRef]

90. Fitch, W.T.; Neubauer, J.; Herzel, H. Calls out of chaos: The adaptive significance of nonlinear phenomena in mammalian vocal production. Anim. Behav. 2002, 63, 407-418. [CrossRef]

91. Koren, L. Hyrax Socialization: First Evidence for a Matriarchal Society. Master's Thesis, Department of Zoology, Tel-Aviv University, Tel Aviv, Israel, 2000.

92. Koren, L. Vocalization as an Indicator of Individual Quality in the Rock Hyrax. Ph.D. Thesis, Department of Zoology, Tel-Aviv University, Tel Aviv, Israel, 2006.

93. Kershenbaum, A.; Ilany, A.; Blaustein, L.; Geffen, E. Syntactic structure and geographical dialects in the songs of male rock hyraxes. Proc. R. Soc. B 2012, 279, 2974-2981. [CrossRef] [PubMed]

94. Demartsev, V.; Kershenbaum, A.; Ilany, A.; Barocas, A.; Bar Ziv, E.; Koren, L.; Geffen, E. Male hyraxes increase song complexity and duration in the presence of alert individuals. Behav. Ecol. 2014, 25, 1451-1458. [CrossRef]

95. Becker, M.L.; Buder, E.H.; Ward, J.P. Spectrographic description of vocalizations in captive Otolemur garnettii. Int. J. Primatol. 2003, 24, 415-446. [CrossRef]

96. De Yong, Y.; Butynski, T.M. Primates of East Africa: Pocket Identification Guide; Global Wildlife Conservation: Austin, TX, USA, 2018; ISBN 978-0-692-13025-4.

97. Butynski, T.M.; de Jong, Y.A. Paragalago cocos, The IUCN Red List of Threatened Species 2019: e.T136212A17963050. 2016. Available online: https://www.iucnredlist.org/species/136212/17963050 (accessed on 15 November 2020).

98. Burgess, N.D.; Fjeldså, J.; Botterweg, R. Faunal importance of the Eastern Arc Mountains of Kenya and Tanzania. J. East Afr. Nat. Hist. 1998, 87, 37-58. [CrossRef]

99. Stanley, W.T.; Kihaule, P.M.; Howell, K.M.; Hutterer, R. Small mammals of the Eastern Arc Mountains, Tanzania. J. East Afr. Nat. Hist. 1998, 87, 91-100. [CrossRef]

100. Demos, T.C.; Kerbis Peterhans, J.C.; Agwanda, B.; Hickerson, M.J. Uncovering cryptic diversity and refugial persistence among small mammal lineages across the Eastern Afromontane biodiversity hotspot. Mol. Phylogenet. Evol. 2014, 71, 41-54. [CrossRef]

Publisher's Note: MDPI stays neutral with regard to jurisdictional claims in published maps and institutional affiliations.

(C) 2020 by the authors. Licensee MDPI, Basel, Switzerland. This article is an open access article distributed under the terms and conditions of the Creative Commons Attribution (CC BY) license (http://creativecommons.org/licenses/by/4.0/). 